\title{
Self-Nanoemulsifying Drug Delivery System of Genkwanin: A Novel Approach for Anti-Colitis-Associated Colorectal Cancer
}

This article was published in the following Dove Press journal: Drug Design, Development and Therapy

\author{
Hua-Feng Yin $\mathbb{1 D}^{1,2}$ \\ Chun-Ming $\mathrm{Yin}^{3}$ \\ Ting Ouyang ${ }^{4}$ \\ Shu-Ding Sun $\mathbb{D}^{\prime}$ \\ Wei-Guo Chen' \\ Xiao-Lin Yang ${ }^{5}$ \\ Xin $\mathrm{He}^{6}$ \\ Chun-Feng Zhang'
}

'School of Traditional Chinese Pharmacy, China Pharmaceutical University, Nanjing, 210009, Jiangsu, People's Republic of China; ${ }^{2}$ Jiangxi QingFeng Pharmaceutical Co., Ltd, Ganzhou, 341000, Jiangxi, People's Republic of China; ${ }^{3}$ Emergency Department, The First Affiliated Hospital of Gannan Medical University, Ganzhou, 341000, Jiangxi, People's Republic of China; ${ }^{4}$ School of Chinese Materia Medical, Beijing University of Chinese Medicine, Beijing, People's Republic of China; ${ }^{5}$ Shanghai University of Traditional Chinese Medicine, Shanghai, 20I203, People's Republic of China; ${ }^{6}$ School of Biomedical Sciences, Faculty of Medicine, The Chinese University of Hong Kong, Hong Kong SAR, People's Republic of China

Correspondence: Xin He

School of Biomedical Sciences, Faculty of Medicine, The Chinese University of Hong Kong, Shatin, Hong Kong SAR,

People's Republic of China

Tel +852-54445989

Email xhe06@qub.ac.uk

Chun-Feng Zhang

School of Traditional Chinese Pharmacy,

China Pharmaceutical University, Nanjing,

210009 , People's Republic of China

Tel +86-25-86185I29

Email zhangchunfeng67@I63.com
Purpose: The aim of the present study was to develop an optimized Genkwanin (GKA)loaded self-nanoemulsifying drug delivery system (SNEDDS) formulation to enhance the solubility, intestinal permeability, oral bioavailability and anti-colitis-associated colorectal cancer (CAC) activity of GKA.

Methods: We designed a SNEDDS comprised oil phase, surfactants and co-surfactants for oral administration of GKA, the best of which were selected by investigating the saturation solubility, constructing pseudo-ternary phase diagrams, followed by optimizing thermodynamic stability, emulsification efficacy, self-nanoemulsification time, droplet size, transmission electron microscopy (TEM), drug release and intestinal permeability. In addition, the physicochemical properties and pharmacokinetics of GKA-SNEDDS were characterized, and its anti-colitis-associated colorectal cancer (CAC) activity and potential mechanisms were evaluated in AOM/DSS-induced C57BL/6J mice model.

Results: The optimized nanoemulsion formula (OF) consists of Maisine CC, Labrasol ALF and Transcutol HP in a weight ratio of 20:60:20 (w/w/w), in which ratio the OF shows multiple improvements, specifically small mean droplet size, excellent stability, fast release properties as well as enhanced solubility and permeability. Pharmacokinetic studies demonstrated that compared with GKA suspension, the relative bioavailability of GKA-SNEDDS was increased by $353.28 \%$. Moreover, GKA-SNEDDS not only significantly prevents weight loss and improves disease activity index (DAI) but also reduces the histological scores of inflammatory cytokine levels as well as inhibiting the formation of colon tumors via inducing tumor cell apoptosis in the AOM/DSS-induced CAC mice model.

Conclusion: Our results show that the developed GKA-SNEDDS exhibited enhanced oral bioavailability and excellent anti-CAC efficacy. In summary, GKA-SNEDDS, using lipid nanoparticles as the drug delivery carrier, can be applied as a potential drug delivery system for improving the clinical application of GKA.

Keywords: insoluble herbal drug, nanoparticle-based drug delivery system, intestinal permeability, pharmacokinetics, anticancer efficacy

\section{Introduction}

Colorectal cancer is the third most common malignancy with considerably high morbidity and mortality worldwide, especially in the United States, Europe and some Asian countries. ${ }^{1}$ It is widely recognized that ulcerative colitis (UC) and Crohn's disease (CD) are both important etiological factors of inflammatory bowel disease (IBD) associated intestinal cancers, ${ }^{2}$ while the long-term development of IBD can directly result in continuous epithelial injury and eventually 
lead to CAC susceptibility. ${ }^{3}$ Chronic inflammation, which promotes tumorigenesis by immune cells producing cytokines, is considered as a key driver of this progression. ${ }^{4}$ Increased expression of a few inflammation-related genes, namely tumor necrosis factor (TNF)$\alpha$, interleukin (IL)-6, interferon (IFN)- $\gamma$ and interleukin (IL)-1 $\beta$, has been observed in CAC. ${ }^{5-7}$ Therefore, enhancing immunity and suppressing tumor-related inflammation has aroused intense interests from researchers in order to suppress CAC.

GKA (Figure 1A), a typical bioactive non-glycosylated flavonoid isolated from Genkwa Flos (Daphne Genkwa Sieb.et Zucc.), is usually used for quality control of Genkwa flos in Chinese Pharmacopoeia. To date, many researches indicate that GKA has exhibited potent effects in anti-inflammatory, ${ }^{8}$ radical scavenging, ${ }^{9}$ immunomodulatory, ${ }^{10}$ antibacterial ${ }^{11}$ and anti-rheumatoid arthritis. $^{12}$ Besides, our previous study has shown that GKA could inhibit tumor cell proliferation partly by enhancing host immunity and reducing inflammatory factor levels. ${ }^{13}$ However, the low aqueous solubility $(<1 \mu \mathrm{g} /$ $\mathrm{mL}$ ) and low permeability of GKA severely limit its clinical practice. ${ }^{14,15}$ It is thus necessary to improve the solubility and bioavailability of GKA for the purpose of enhancing its further application in CAC treatment.

Self-nanoemulsifying drug delivery system (SNEDDS) is an anhydrous nanoemulsion formulation composes of oil, surfactant, cosurfactant and drug. In vitro, the nanoemulsion forms spontaneously after adding an aqueous phase followed by gentle stir. In vivo, the formation of nanoemulsion with the droplet size in the range of 20-200 $\mathrm{nm}$ can be triggered by gentle peristaltic agitation of the gastrointestinal (GI) tract. $^{16-18}$ Smaller globule size provides SNEDDS with a larger interfacial surface area, which could consequently improve its drug absorption and bioavailability by enhancing drug release and membrane permeation, reducing pre-systemic metabolism, and inhibiting efflux pump. ${ }^{19}$ Nowadays, there are extensive interests in SNEDDS due to their potential in optimizing the oral bioavailability of insoluble herbal drugs, especially in flavonoid compounds, namely naringenin, ${ }^{20}$ rutin and myricetin. $^{21}$ In recent years, the studies of SNEDDS have opened up a promising new avenue to the increase of drug solubility, reduction of side-effects and enhancement of anti-tumor capacity. ${ }^{22,23}$

The aim of this study was to optimize a formulation to improve GKA solubility, bioavailability, and anti-CAC activity (Scheme 1). The optimized formulation (OF) was evaluated by physicochemical properties, droplet size, polydispersity index, zeta potential, morphology, stability and release test. Meanwhile, intestinal permeability and pharmacokinetic parameter of the OF were investigated. Besides, we also assessed the effects of OF in parallel to GKA-suspension on AOM/DSS -induced C57BL/6J mice model.

\section{Materials and Methods}

\section{Reagents and Animals}

Genkwanin (purity $>98 \%$ ) was purchased from Cao Yuan Kang Biotechnology Co., Ltd. (Chengdu, China). Labrafil M1944CS (Oleoyl polyoxyl-6 glycerides), Maisine CC (glyceryl monolinoleate), Lauroglycol 90 (Ppropylene glycol monolaurate), Capryol 90 (propylene glycol monocaprylate), Labrasol ALF (caprylocaproyl polyoxyl-8 glycerides), Transcutol HP (diethylene glycol monoethyl ether) were supplied by Gattefossé (Saint-Priest Cedex, France). Kolliphor HS 15 (macrogol 15 hydroxy stearate), CremophorRH40 (polyoxyl 40 hydrogenated castor oil) were kindly donated by BASF (Ludwigshafen, Germany). Olive oil, castor oil, Tween 80, Glycerin, propylene glycol, and polyethylene glycol 400 were purchased from Nanjing Chemical Reagent Co., Ltd. (Nanjing, China). Azoxymethane (AOM) was purchased from Sigma-Aldrich Co. LLC (St. Louis, MO, USA). Dextran sulfate sodium (DSS, 36-50 kDa) was purchased from MP Biomedical, Inc. (Solon, OH, USA).

Mouse IL-1 $\beta$, IL-6, IL-8, IL-10, TNF- $\alpha$ and INF- $\gamma$ ELISA kits were obtained from Senbeijia Biotechnology Co., Ltd. (Nanjing, China).

Male Sprague Dawley rats (body weight 250-300g) and Male C57BL/6J mice (body weight 18-22g) were obtained from the Hunan SJA Laboratory Animal Co., Ltd. (Certificate No. SCXK (xiang) 2019-0004, Hunan, China). Animal welfare and experimental procedures were carried out in strict accordance with the Guide for the Care and Use of Laboratory Animals (Institute of Laboratory Animal Resources Commission on Life Sciences National Research Council National Academy Press Washington, D.C.) and approved by the Institutional Animal Ethics Committee in Jiangxi Qing Feng Pharmaceutical Co., Ltd (permission No. 193,410,007). All animals performed in studies were in accordance with the ethical standards of the institution or practice at which the studies were conducted. 
<smiles>COc1cc(O)c2c(=O)cc(-c3ccc(O)cc3)oc2c1</smiles>

C
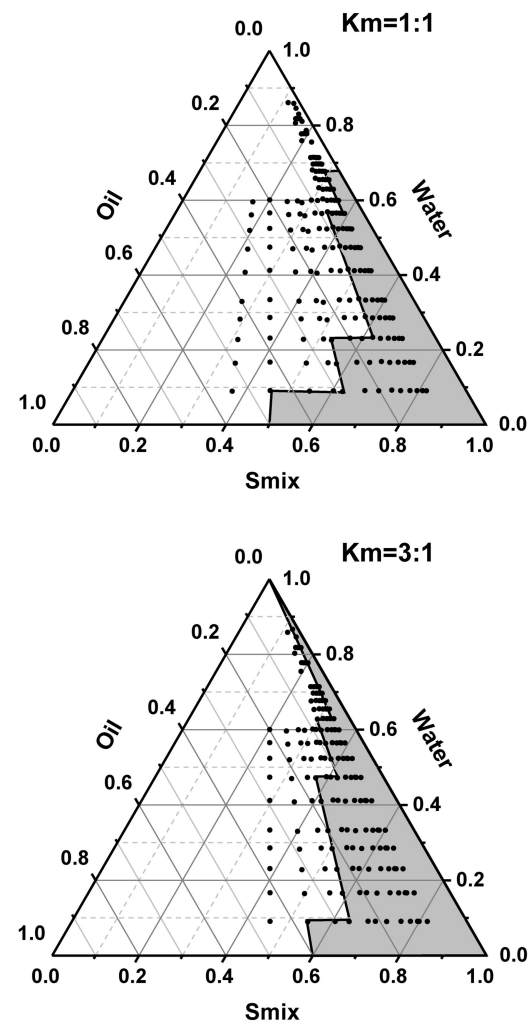

D

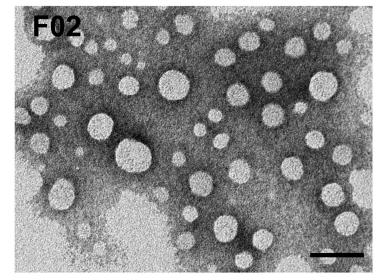

B

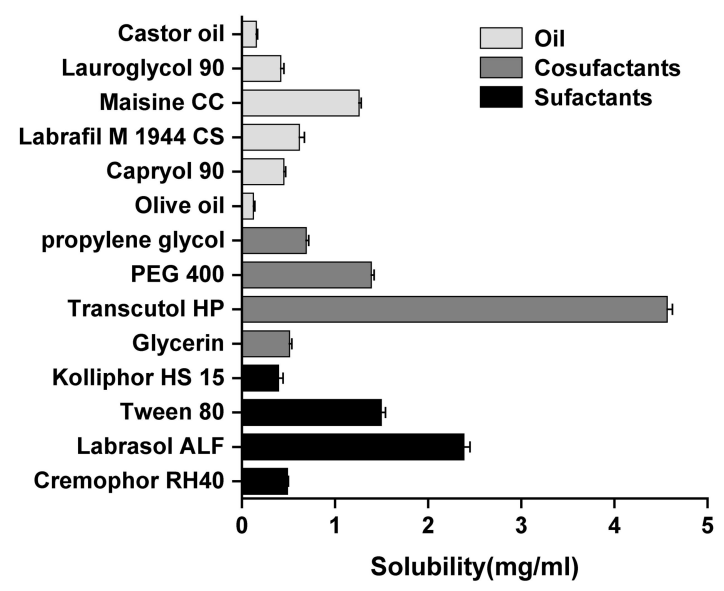

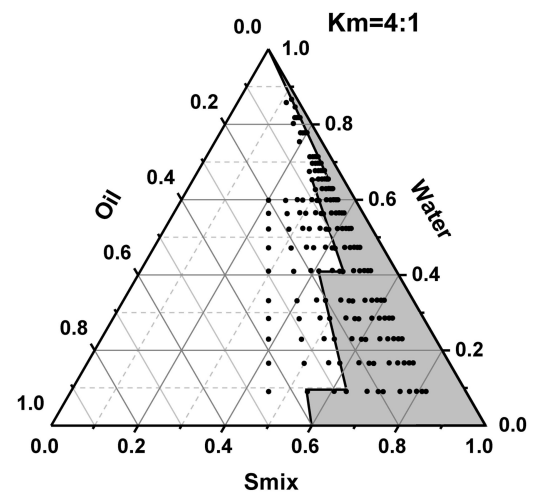



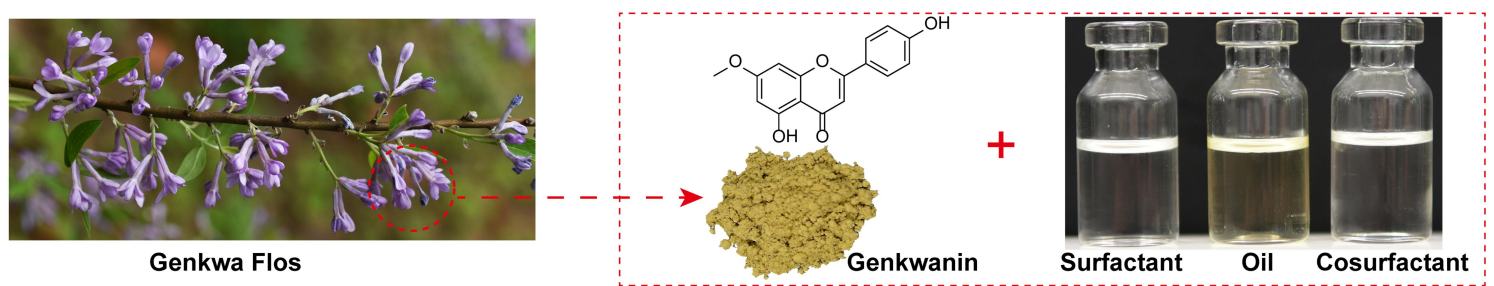

Genkwa Flos
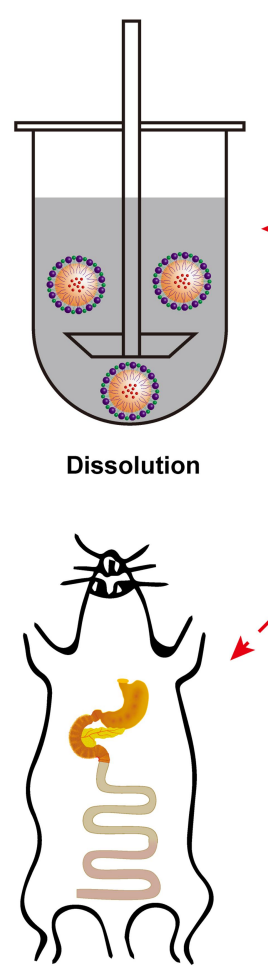

Intestinal permeability
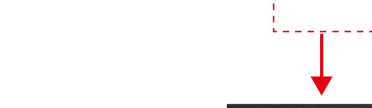

Surfactant

Oil Cosurfactant

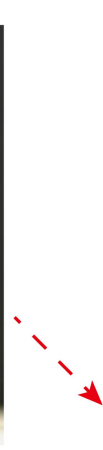

GKA-SNEDDS

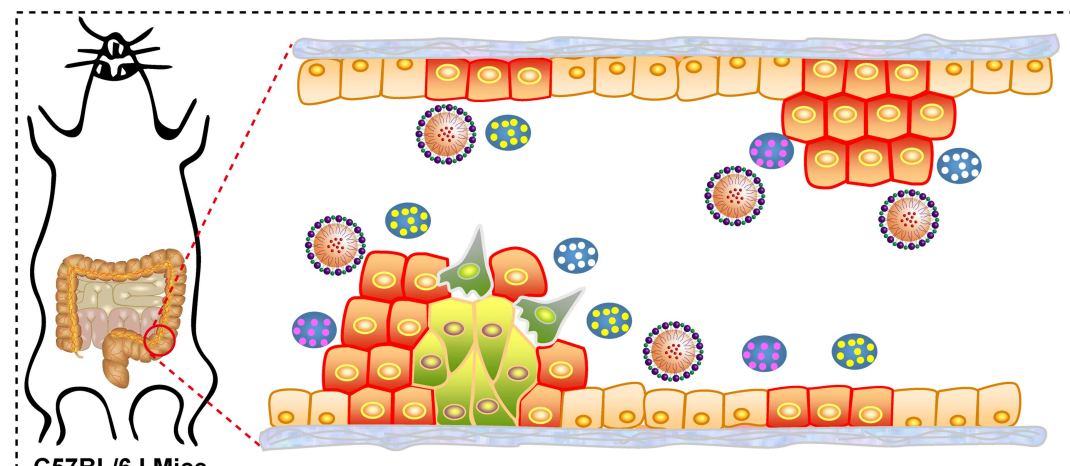

C57BL/6J Mice

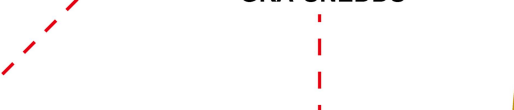

I

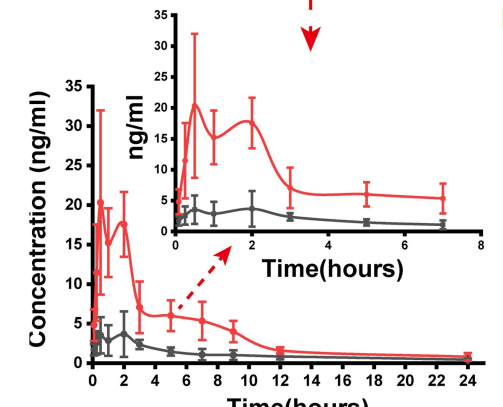

Time(hours)

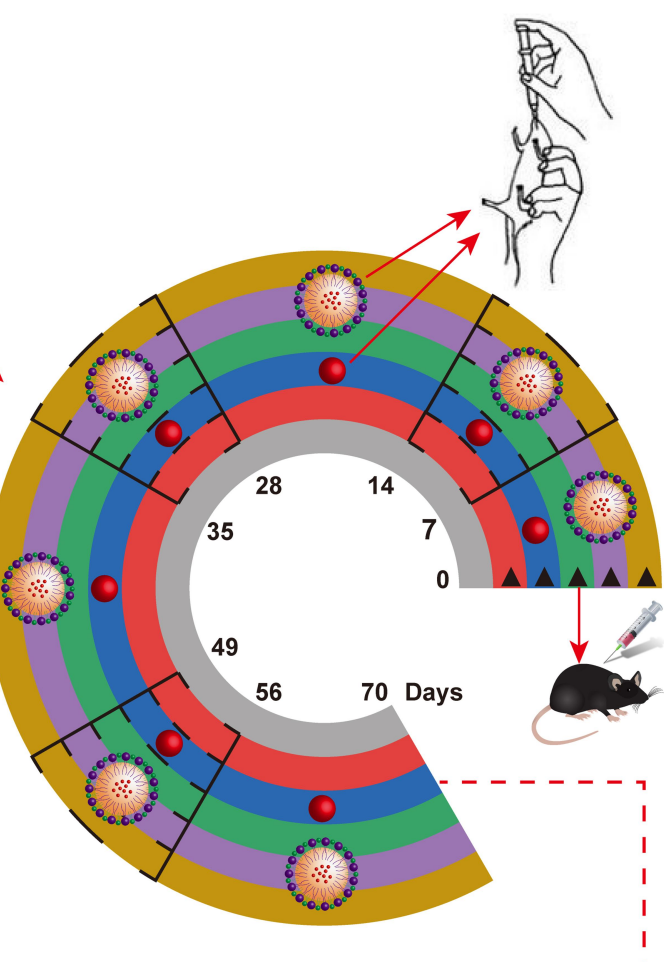

Colitis Associated Colorectal Cancer procedure

tr

\begin{tabular}{|c|c|c|c|c|}
\hline Control & GKA-SNEDDS(L) & $\triangle \mathrm{AOM}$ & (3) GKA-SNEDDS & Inflammatory cells \\
\hline Model & GKA-SNEDDS(M) & DSS & () Normal cell & o) Invasive cell \\
\hline GKA-suspension & GKA-SNEDDS(H) & GKA & Transformed cell & Metastatic cell \\
\hline
\end{tabular}

Scheme I Evaluation of SNEDDS for genkwanin in vitro and in vivo.

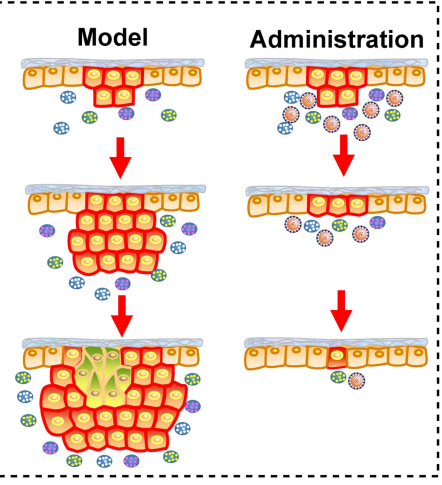




\section{Optimizing of SNEDDS Formulation}

\section{Components}

\section{Solubility Study}

Excess GKA was added into stop-glass bottles containing a total of $1 \mathrm{~mL}$ of oil, surfactant or cosurfactant phase. All the samples were mixed with vortex for 10 minutes at $25^{\circ} \mathrm{C}$ and then were gently shaken for another 24 hours at $37^{\circ} \mathrm{C}$. After the gentle shake, the mixtures were centrifuged at 12,000 rpm for 10 minutes and the supernatants were collected. Subsequently, we diluted the supernatants with methanol and filtered them with a glass fiber filter (25mm, Waters). The concentration of GKA was measured at $338 \mathrm{~nm}$ by HPLC. Each experiment was repeated in triplicate.

\section{Construction of Pseudo-Ternary Phase Diagrams}

Based on the results of solubility studies, the pseudoternary phase diagrams of oils (Maisine CC), surfactants (Labrasol ALF), and cosurfactants (Transcutol HP) were obtained by the water titration method to determine the existence range of the self-micro-emulsifying region.

With the aim of obtaining optimal solubility of GKA and the stability of the self-emulsion, a series of different ratios of oil, surfactant and cosurfactant $\left(\mathrm{S}_{\text {mix }}\right)$ were selected. The selected $S_{\text {mix }}$ ratios were 1:1, 2:1, 3:1, and $4: 1$, when the mixture of oil and $\mathrm{S}_{\text {mix }}$ weight ratios were 1:9, 1:8, 1:7, 1:6, 1:5, 2:8 (1:4), 1:3.5, 1:3,3:7 (1:2.3), 1:2, 4:6 (1:1.5), 5:5 (1:1), 6:4 (1:0.7), 7:3 (1:0.43), 8:2 (1:0.25),
9:1 (1:0.1). Each mixture was added into a round-bottom flask and stirred vigorously with magnetic stirrers at $150 \mathrm{rpm}$ for $5 \mathrm{~min}$. The mixture was then titrated with distilled water until it formed a transparent self-emulsion with a faint blue light by visual observation. The pseudoternary phase diagrams were constructed by the use of the software Origin 2018. Each experiment was repeated in triplicate.

\section{Preparation of GKA-SNEDDS and Formulation Optimization}

The prepared SNEDDS formulations of GKA along with their compositions and codes are listed in Table 1. Moreover, to investigate the self-nanoemulsifying properties of GKA-SNEDDS, the thermodynamic stability and emulsifying effect of these formulations were tested.

\section{Thermodynamic Stability Tests}

Thermodynamic stability tests are composed of three parts: centrifugation, heating-cooling cycle and freezethaw cycle. ${ }^{24}$ First, the selected formulations were centrifuged at $3500 \mathrm{rpm}$ for 30 minutes in order to determine the stability of as an isotropic single-phase system. Subsequently, the formulations that did not show any phase separations, creaming or cracking were subjected to six heating and six cooling cycles, in which samples were incubated at $4{ }^{\circ} \mathrm{C}$ or $45{ }^{\circ} \mathrm{C}$ for every 48 hours, respectively. Finally, the stable formulations at these temperatures were treated with three further freeze-

Table I Thermodynamic Stability and Emulsification Efficacy Test of GKA-SNEDSS

\begin{tabular}{|c|c|c|c|c|c|c|c|c|}
\hline \multirow[t]{2}{*}{$\begin{array}{l}\text { Formulation } \\
\text { Code }\end{array}$} & \multirow[t]{2}{*}{$\begin{array}{l}S_{\text {mix }} \text { Ratio } \\
(w / w)\end{array}$} & \multicolumn{2}{|c|}{ Formulation Composition } & \multicolumn{3}{|c|}{$\begin{array}{l}\text { Thermodynamic } \\
\text { Stability Studies }\end{array}$} & \multicolumn{2}{|c|}{$\begin{array}{l}\text { Emulsification } \\
\text { Efficacy Test ( } 1: 500)\end{array}$} \\
\hline & & $\begin{array}{l}\text { GKA } \\
(\mathrm{mg} / \mathrm{mL})\end{array}$ & $\begin{array}{l}\text { Maisine CC/Labrasol ALF/Transcutol } \\
\text { HP }(\%, w / w / w)\end{array}$ & Cent & $\mathrm{HCC}$ & FTC & $\begin{array}{l}\text { Distilled } \\
\text { Water }\end{array}$ & $\begin{array}{l}0 . \mathrm{IN} \\
\mathrm{HCl}\end{array}$ \\
\hline FOI & I:I & 0.50 & 15:42.5:42.5 & $\sqrt{ }$ & $\sqrt{ }$ & $\sqrt{ }$ & Grade B & Grade B \\
\hline F02 & & 0.50 & $20: 40: 40$ & $\sqrt{ }$ & $\sqrt{ }$ & $\sqrt{ }$ & Grade B & Grade B \\
\hline F03 & & 0.50 & $25: 37.5: 37.5$ & $\sqrt{ }$ & $\sqrt{ }$ & $\sqrt{ }$ & Grade D & Grade D \\
\hline F04 & $2: 1$ & 0.50 & I5:56.67:28.33 & $\sqrt{ }$ & $\sqrt{ }$ & $\sqrt{ }$ & Grade B & Grade B \\
\hline F05 & & 0.50 & $20: 53.33: 26.67$ & $\sqrt{ }$ & $\sqrt{ }$ & $\sqrt{ }$ & Grade B & Grade B \\
\hline F06 & & 0.50 & $25: 50: 25$ & $\sqrt{ }$ & $\sqrt{ }$ & $\sqrt{ }$ & Grade C & Grade C \\
\hline F07 & $3: 1$ & 0.50 & $15: 75: 15$ & $\sqrt{ }$ & $\sqrt{ }$ & $\sqrt{ }$ & Grade B & Grade B \\
\hline F08 & & 0.50 & $20: 60: 20$ & $\sqrt{ }$ & $\sqrt{ }$ & $\sqrt{ }$ & Grade A & Grade A \\
\hline F09 & & 0.50 & $25: 56.25: 18.75$ & $\sqrt{ }$ & $\sqrt{ }$ & $\sqrt{ }$ & Grade C & Grade C \\
\hline FIO & $4: 1$ & 0.50 & I5:68:17 & $\sqrt{ }$ & $\sqrt{ }$ & $\sqrt{ }$ & Grade B & Grade B \\
\hline FII & & 0.50 & $20: 64: 16$ & $\sqrt{ }$ & $\sqrt{ }$ & $\sqrt{ }$ & Grade A & Grade A \\
\hline $\mathrm{FI} 2$ & & 0.50 & $25: 60: 15$ & $\sqrt{ }$ & $\sqrt{ }$ & $\sqrt{ }$ & Grade C & Grade C \\
\hline
\end{tabular}

Note: $\sqrt{ }$, Indicates the formulation passed the test.

Abbreviations: Cent, centrifugation ( $3500 \mathrm{rpm}$ for 30 minutes); $\mathrm{HCC}$, heating-cooling cycle (six heating and six cooling cycles, $4{ }^{\circ} \mathrm{C}$ and $45^{\circ} \mathrm{C}$ for every 48 hours); $\mathrm{FTC}$, freeze- thaw cycle (between $-20^{\circ} \mathrm{C}$ and $25 \pm 2{ }^{\circ} \mathrm{C}$ in deep-freezer). 
thaw cycles at temperatures between $-20{ }^{\circ} \mathrm{C}$ and $25 \pm 2$ ${ }^{\circ} \mathrm{C}$ in deep-freezer (Cooling System, Martin Christ), the treated time should not be less than 48 hours.

\section{Emulsification Efficacy Tests}

GKA-SNEDSS formulation $(1 \mathrm{~mL})$ was dispersed into $500 \mathrm{~mL}$ of distilled water and $0.1 \mathrm{~N} \mathrm{HCl}$, in a standard dissolution apparatus (SOTAX AT 7, Sotax Group, Switzerland). The speed of dissolution paddle was kept at $50 \mathrm{rpm}$ to provide the formulation with gentle mixing and the dissolution temperature was maintained at $37 \pm 0.5{ }^{\circ} \mathrm{C}$. The visual evaluation of the in vitro performance of the formulations was carried out with five grading systems according to the following classification (Table 2). ${ }^{25,26}$

\section{Preparation of GKA-SNEDDS}

GKA-SNEDDS was prepared using Maisine CC, Labrasol ALF, and Transcutol HP. Firstly, GKA was dissolved in Maisine CC and then mixed with Labrasol ALF and Transcutol HP in a gentle magnetic stirring environment ( $300 \mathrm{rpm}, 25{ }^{\circ} \mathrm{C}$ for 30 minutes). The formulations (F02, F05, F08 and F11) were chosen as candidates for further investigation of their dispersibility and selfnanoemulsifying properties.

\section{Characterization of GKA-SNEDDS}

\section{Time for Self-Nanoemulsification}

The self-nanoemulsification time of GKA-SNEDDS was evaluated on dissolution apparatus (SOTAX AT 7, Sotax Group, Switzerland). Briefly, the selected formulations of GKA-SNEDDS were added dropwise to $500 \mathrm{~mL}$ of

Table 2 Visual Evaluation of Self-Emulsification Behavior

\begin{tabular}{|l|l|l|}
\hline Grade & Dispersibility and Appearance & $\begin{array}{l}\text { Emulsification } \\
\text { Time (Seconds) }\end{array}$ \\
\hline A & $\begin{array}{l}\text { Rapidly forming nanoemulsion which } \\
\text { is clear or bluish appearance }\end{array}$ & $<60 \mathrm{~S}$ \\
\hline B & $\begin{array}{l}\text { Rapidly forming, slightly less clear } \\
\text { emulsion which has a bluish white } \\
\text { appearance }\end{array}$ & $<60 S$ \\
\hline C & $\begin{array}{l}\text { Fine milky emulsion, similar to milk in } \\
\text { appearance }\end{array}$ & $<120 \mathrm{~S}$ \\
\hline D & $\begin{array}{l}\text { Slow to emulsion, dull, grayish white } \\
\text { emulsion with slightly oily appearance }\end{array}$ & $>120 \mathrm{~S}$ \\
\hline E & $\begin{array}{l}\text { Poor or minimal emulsification with } \\
\text { large oil globules noticed on the surface }\end{array}$ & $>180 \mathrm{~S}$ \\
\hline
\end{tabular}

distilled water, of which the temperature was kept at $37{ }^{\circ} \mathrm{C} \pm 0.5{ }^{\circ} \mathrm{C}$. Moreover, a standard stainless steel dissolving paddle rotating at $50 \mathrm{rpm}$ is used for gentle stir to obtain a clear and uniform system. The emulsification time was assessed visually ${ }^{27}$ and the assessments were performed in triplicate as well.

\section{Droplet Size Analysis and Zeta Potential}

The droplet size and the polydispersity index (PDI) of each nanoemulsion were evaluated by the Zetasizer (Malvern Instruments, Malvern, UK). After diluting the GKA-SNEDDS formulation with distilled water at $37^{\circ} \mathrm{C}$, samples were directly evaluated in triplicate.

\section{Assessment of Entrapment Efficiency}

GKA-SNEDDS formulations (with a known amount of GKA) were added to $500 \mathrm{~mL}$ of distilled water and centrifuged at $12,000 \mathrm{rpm}$ for 10 minutes at $37^{\circ} \mathrm{C}$. Followed by the HPLC measurement of GKA amount in the supernatants, the entrapment efficiency (EE) was calculated by the following equation. ${ }^{28}$

$$
\mathrm{EE}(\%)=\frac{\mathrm{W}_{\text {Total GKA }}-\mathrm{W}_{\text {Unentrapped GKA }}}{\mathrm{W}_{\text {Total GKA }}} \times 100 \%
$$

\section{Surface Morphology Detection}

The selected SNEDDS surface morphology was characterized by transmission electron microscopy (HT7700, Hitachi, Tokyo, Japan). After diluting the nanoemulsions with water, droplets were placed on gold sputter-coated copper grids. Then, the excess droplets were separated by filter paper and the remaining nanoemulsions on the gold sputter-coated copper grids were left to dry in the dark before staining with phosphotungstic acid (2\%) prior to observation.

\section{In vitro Drug Release Evaluation}

The release profiles of GKA-SNEDDS formulations were performed using a drug dissolution tester (SOTAX AT 7, Sotax Group, Switzerland) according to USP $<711>$ dissolution test Apparatus II (paddle method). The paddle rotation speed at $50 \mathrm{rpm}$ and a temperature of $37{ }^{\circ} \mathrm{C} \pm$ $0.5{ }^{\circ} \mathrm{C}$ were maintained in this test. Briefly, aliquots of GKA-SNEDDS (equivalent to $5 \mathrm{mg}$ of GKA) or GKAsuspension (GKA suspended in $0.5 \% \mathrm{CMC}-\mathrm{Na}$ ) was placed in a dialysis bag (molecular weight cut-off 100KD) and added to $250 \mathrm{~mL}$ of artificial gastric juice (2\% Triton $\mathrm{X}-100, \mathrm{HCl}, \mathrm{pH} 1.2)$ or artificial intestinal juice ( $2 \%$ Triton X-100, PBS, $\mathrm{pH}$ 6.8) respectively. Then, $5 \mathrm{~mL}$ of each solution was taken out at $0,2,4,8$, 
12, 24, 36 and $72 \mathrm{~h}$ and replaced with an equal volume of fresh medium. Finally, the samples were filtered using a $25 \mathrm{~mm}$ glass fiber filter and then analyzed by HPLC.

\section{Intestinal Permeability Study}

The intestinal permeability of the selected formulations (F02, F05, F08 and F11) was evaluated in single-pass intestinal perfusion (SPIP) model as the previous report. $^{29}$ Male Sprague Dawley rats (body weight 250 $300 \mathrm{~g}, \mathrm{n}=15$ ) were randomly divided into five groups with free access to water. The animals were fasted for 12 hours before the experiment. Firstly, GKA-SNEDDS (containing $2.5 \mathrm{mg}$ GKA) or GKA-suspension was ultrasonically dispersed in $500 \mathrm{~mL}$ Krebs-Ringer buffer solution and treated with $37{ }^{\circ} \mathrm{C}$ water bath to obtain perfusion solution. Then, a single-pass constant flow $(0.2 \mathrm{~mL} / \mathrm{min})$ of solution was perfused into ligated rat duodenum and jejuna segments. When the stable state was achieved (after approximately $30 \mathrm{~min}$ ), the samples were regularly taken out for $90 \mathrm{~min}$ at $15 \mathrm{~min}$ intervals and then centrifuged at 12000rpm for $10 \mathrm{~min}$. The supernatants were collected and then filtered with a glass fiber filter (25 mm, Waters), followed by HPLC analysis. The lengths of the tested sample segments were measured at the end of the perfusion. The effective permeability coefficient was calculated by the following equations. $^{30,31}$

$$
\begin{gathered}
\mathrm{P}_{\text {eff }}=-Q \ln \left(\frac{\mathrm{C}_{\text {out }(\text { corrected })}}{\mathrm{C}_{\text {in }}}\right) / 2 \pi \mathrm{r} l \\
\mathrm{C}_{\text {out }(\text { corrected })}=\frac{\mathrm{C}_{\text {out }} \times \mathrm{V}_{\text {out }}}{\mathrm{V}_{\text {in }}}
\end{gathered}
$$

where $P_{\text {eff }}$ is the effective permeability coefficient $(\mathrm{cm} / \mathrm{s})$, $\mathrm{Q}$ is the flow rate of perfusion solution $(0.2 \mathrm{~mL} / \mathrm{min}), \mathrm{C}_{\text {in }}$ is the concentrations of the GKA in the inlet perfused $(\mu \mathrm{g} / \mathrm{mL})$, $\mathrm{C}_{\text {out }}$ is the corrected concentration of the GKA in the outlet perfused $(\mu \mathrm{g} / \mathrm{mL}) . V_{\text {in }}$ and $V_{\text {out }}$ are the entering and exiting volume of the perfusion solution $(\mathrm{mL}), \mathrm{r}$ is the rat intestinal radius $(\mathrm{cm})$, and $l$ is the length of the intestinal segment $(\mathrm{cm})$.

\section{In vivo Pharmacokinetic Study}

The pharmacokinetic study of optimized formulation (F08) was evaluated in male Sprague Dawley rats (body weight 250-300g, $\mathrm{n}=12$ ). All the animals were randomly divided into two groups with free access to water. The animals were fasted for 12 hours before the experiment. Then, the animals of two groups were treated with a single dose of the GKA-suspension or the GKA-SNEDDS (F08 formulation) at $125 \mathrm{mg} / \mathrm{kg}$, respectively. After the GKA treatments, blood samples $(0.20 \mathrm{~mL}$ each $)$ were collected from the eye socket veins of rats at $5,15,30,60,120,180$, 300, 420, 540, 720 and 1440 minutes. By the means of centrifugation $(12,000 \mathrm{rpm}, 10$ minutes $)$, the plasma was collected and stored at $-80^{\circ} \mathrm{C}$ for further evaluations. Moreover, in order to avoid the influence of protein in the plasma, acetonitrile $(3.0 \mathrm{~mL})$ was added into the mixture and the mixture was vortexed for 2 minutes. Subsequently, after centrifugation for another 10 minutes $(12,000 \mathrm{rpm})$, the supernatant was collected and dried with nitrogen blow in the environment of $-0.8 \mathrm{Mpa}$ at $25^{\circ} \mathrm{C}$. The residue was redissolved with $200 \mu \mathrm{L}$ acetonitrile/ water $(\mathrm{v} / \mathrm{v})$. Finally, after another centrifugation (12,000rpm, 10 minutes), the supernatant was collected and analyzed with the LC-MS/MS system. The relative bioavailability (F) of GKA was calculated by the following equation. $^{32}$

$$
\mathrm{F}=\frac{\mathrm{AUC}_{\mathrm{GKA}-\mathrm{SNEDDS}}}{\mathrm{AUC}_{\mathrm{GKA}-\text { suspension }}} \times 100 \%
$$

\section{The Therapeutic Effect of GKA-SNEDDS on AOM/DSS-Induced CAC Mice The Establishment of AOM/DSS-Induced CAC Model and Administration}

Male C57BL/6J mice (body weight 18-22 g) were administrated under standard conditions of alternating $12 \mathrm{~h}$ dark and light cycles at $24 \pm 2{ }^{\circ} \mathrm{C}$ with relative humidity of $50 \pm 10 \%$. The animals were separated into 6 groups ( $n=8$ per group), the normal control or control group, the AOM/DSS or model group, GKA-suspension (GKA suspended in 0.5\% CMC-Na, $22.5 \mathrm{mg} / \mathrm{kg} /$ day), GKA-SNEDDS (L) (low-dosage, $2.5 \mathrm{mg}$ / $\mathrm{kg} /$ day), GKA-SNEDDS (M) (medium-dosage, $7.5 \mathrm{mg} / \mathrm{kg} /$ day), GKA-SNEDDS (H) (high-dosage, $22.5 \mathrm{mg} / \mathrm{kg} /$ day). The CAC model mouse was constructed by intra-peritoneal injection of $10 \mathrm{mg} / \mathrm{kg}$ AOM and oral $2.0 \% \mathrm{DSS}^{33,34}$ In brief, except the control group, all the animals received intraperitoneal injection of $\mathrm{AOM}(10 \mathrm{mg} / \mathrm{kg})$ on the first day. Then, all the groups were treated with the corresponding drug system for 1 week after the AOM injection (set as day1). Seven days later, $2.0 \%$ DSS was given in the drinking water over 7 days, followed by 14 days of regular water. The DSS treatments were repeated three times. Animals in the model group were only treated with AOM/DSS without any GKA added. What's more, GKA group was orally administered with a feeding tube every $24 \mathrm{~h}$ for 70 days. Afterwards, 
all mice were sacrificed at the end of the third cycle, colon samples were collected for other evaluations.

\section{Assessment of Body Weight and Disease Activity Index}

The severity of colitis was evaluated with disease activity index (DAI), which is scored by assessing animal body weight, stool consistency and stool bleeding. ${ }^{35}$ These factors were monitored twice a week. The DAI score was calculated based on the sum of these scores, ranging from 0 (healthy) to 12 (severe colitis), according to Table 3.

\section{Assessment of Colon Length and Colonic Tumorigenesis}

The colons (from the ileocecal junction to the anorectal junction) of all the groups were collected and measured with a ruler. The colonic tumorigenesis was assessed as previously reported. ${ }^{36}$ In brief, after rinsing the colon with phosphate-buffered saline, the colon was slit longitudinally along the mesentery to observe its gross morphological changes, and the prominent areas of the colon (which may include cancer) were observed visually. Afterwards, all colons were photographed. The number and size of tumors were evaluated using Image-J software.

\section{Histologic Assessment of Colons}

The colons of each group were collected and cut into small segments $(2 \mathrm{~cm})$, then fixed with $10 \%$ paraformaldehyde, embedded in paraffin blocks, and subsequently stained with hematoxylin and eosin (H\&E). Histological evaluation was assessed by using a light microscope (Nikon ECLIPSE Ti2, Tokyo, Japan). Histological scores were blindly evaluated by two pathologists using the following measures: ${ }^{37}$ crypt architecture (normal,0 points; Severe crypt distortion with loss of entire crypt, 3 points), degree of inflammatory cell infiltration (normal, 0 points; dense inflammatory infiltrate, 3 points), muscle thickening (base

Table 3 Evaluation of Disease Activity Index

\begin{tabular}{|l|l|}
\hline Classification & Characterization (Scores) \\
\hline $\begin{array}{l}\text { Body weight } \\
\text { change }\end{array}$ & $\begin{array}{l}\text { No weight loss or weight gain (0 points),5-10\% } \\
\text { weight loss (I point), I I-15\% weight loss (2 } \\
\text { points), 16-20\% weight loss (3 points), >2 I\% } \\
\text { weight loss (4 points). }\end{array}$ \\
\hline Stool consistency & $\begin{array}{l}\text { Normal and well-formed (0 points), very soft } \\
\text { and unformed (2 points), watery stool (4 points). }\end{array}$ \\
\hline Stool bleeding & $\begin{array}{l}\text { Normal color stool (0 points), reddish color } \\
\text { stool(2 points), bloody stool (4 points). }\end{array}$ \\
\hline
\end{tabular}

of crypt sits on the muscularis mucosae, 0 points; marked muscle thickening present, 3 points), goblet cell depletion (absent,0points; present, 3 points) and crypt abscess (absent, 0points; present, 3 points). The histological disease scorewas calculated from the sum of each individual score.

\section{Assessment of Inflammatory Cytokines}

The colon tissues were homogenized in PBS, according to the instructions of the corresponding manufacturer, the concentration of pro-inflammatory cytokine (IL-1 $\beta$, IL-6, IL-8 and TNF- $\alpha$ ) and anti-inflammatory cytokine (IL-10 and INF- $\gamma$ ) were detected by ELISA kits.

\section{Immunohistochemistry Analysis}

The colons were collected and fixed with $10 \%$ paraformaldehyde, followed by paraffin embedding. Then, the colon paraffin sections were processed for immunohistochemistry. Colon sections were deparaffinised followed by antiPCNA or anti-Ki-67 antibody at a 1:200 dilution.

Apoptotic cells in colonic tissues were labeled with the terminal deoxyribonucleotidyl transferase-mediated dUTP-digoxigenin nick end-labeling (TUNEL) method using an In Situ Apoptosis Detection Kit according to the manufacturer's instructions. Images were captured with an ECLIPSE Ti 2 microscope (Nikon Imaging Japan Inc., Tokyo, Japan) and quantified by counting the number of positively stained cells in eight randomly selected fields. The number of positively stained cells was expressed as a percentage of the total cells in the 10 areas.

\section{Statistical Analysis}

The results are reported as the mean \pm standard deviation (SD). Significant differences were determined by ANOVA followed by Student's $t$-test for multiple comparisons. Differences were considered significant at $p<0.05$.

\section{Results}

\section{Structure Elucidation of GKA}

${ }^{13} \mathrm{C}$ NMR (400 MHz, DMSO-d6) $\delta$ ppm: 182.34 (C-7), 165.52 (C-1), 164.46 (C-9), 161.74 (C-3), 161.63 (C-5), 157.62 (C-17), 128.97 (C-15, C-19), 121.49 (C-14), 116.41 (C-16, C-18), 105.09 (C-8), 103.42 (C-4), 98.35 (C-2), 93.04 (C-6), 56.44 (C-12). ${ }^{1} \mathrm{H}$ NMR (400 MHz, DMSO-d6) $\delta$ ppm: $12.963(1 \mathrm{H}, \mathrm{s}, \mathrm{H}-21), 10.383(1 \mathrm{H}, \mathrm{s}$, $\mathrm{H}-20), 7.956$ (2H, d, J=8.4 Hz, H-15 and H-19), 6.938 $(2 \mathrm{H}, \mathrm{d}, \mathrm{J}=8.4 \mathrm{~Hz}, \mathrm{H}-16$ and $\mathrm{H}-18), 6.839(1 \mathrm{H}, \mathrm{s}, \mathrm{H}-8)$, $6.755(1 \mathrm{H}, \mathrm{d}, \mathrm{J}=1.6 \mathrm{~Hz}, \mathrm{H}-2), 6.368(1 \mathrm{H}, \mathrm{d}, \mathrm{J}=2.0 \mathrm{~Hz}$, 
H-6), 3.868 (3H, s, H-12). IR $\left(\mathrm{KBr}, \mathrm{cm}^{-1}\right): 3280(-\mathrm{OH})$, 1666 (chromone),1589,1500, 1451, 1375, 1342, 1208,833 . By comparing its NMR with the published data, this compound was confirmed to be GKA. ${ }^{38}$ The NMR spectrum of GKA is shown in supplementary Figure $\mathrm{S} 1$ and $\mathrm{S} 2$, and infrared spectrum is shown in supplementary Figure S3.

\section{Development of SNEDDS Formulation Solubility Study}

The purpose of the solubility study is to determine the appropriate oil phase, surfactant and cosurfactant for GKA-SNEDDS development. It has been extensively reported that identifying the appropriate oil, surfactant and cosurfactant with the greatest solubilization potential for the drug under research is very necessary for achieving optimal drug loading. ${ }^{39}$

As shown in Figure 1B, GKA solubility in different solvent media was evaluated by the mentioned method. ${ }^{40}$ We can easily find that Transcutol HP $(4.57 \mathrm{mg} / \mathrm{mL})$ is a commonly used solvent and a powerful solubilizer agent, as well as the most soluble cosurfactant for GKA. Moreover, Maisine CC and Labrasol ALF (1.26 and $2.38 \mathrm{mg} / \mathrm{mL}$, respectively) showed the highest solubilization ability in the oil phase and the surfactant phase. Furthermore, Maisine CC (Glycerol monolinoleate) is an often-used solubilizer for lipophilic drugs and bioavailability enhancer, Labrasol ALF is commonly used in oral selfemulsifying lipid formulation. ${ }^{41}$ Therefore, in this study, Maisine CC, Labrasol ALF, and Transcutol HP were respectively selected as the oil, surfactant, and cosurfactant of GKA-SNEDDS.

\section{Construction of Pseudo-Ternary Phase Diagrams}

Based on the results of the above solubility studies, Maisine CC (oil), Labrasol ALF (surfactant), and Transcutol HP (cosurfactant) were applied to construct the pseudo-ternary phase diagrams. As shown in Figure $1 C$, different ratios of $S_{\text {mix }}(1: 1,2: 1,3: 1$, and $4: 1$ for Labrasol ALF:Transcutol HP) generated similar nanoemulsion areas $\left(\mathrm{K}_{\mathrm{m}}=3: 1>\mathrm{K}_{\mathrm{m}}=4: 1>\mathrm{K}_{\mathrm{m}}=2: 1>\mathrm{K}_{\mathrm{m}}=1: 1\right)$. When surfactant concentration was increased to $S_{\text {mix }}$ ratio $4: 1$, it was seen that nanoemulsion area decreased as compared to 3:1 ratio. While cosurfactant concentration was further increased to $S_{\text {mix }}$ ratio 1:1, it was observed that the nanoemulsion area decreased as compared to $\mathrm{S}_{\text {mix }}$ ratio $2: 1$. This result indicated that $S_{\text {mix }}$ ratio played a significant role in promoting self-emulsification. ${ }^{16}$
Moreover, regarding the excellent emulsification capability of Labrasol ALF and Transcutol HP as well as the prominent solubility of GKA in Maisine $\mathrm{CC}$, the proportion of SNEDDS formulations was further optimized.

\section{Formulation Optimization}

According to the pseudo-ternary phase diagrams and preset drug concentrations $(0.5 \mathrm{mg} / \mathrm{mL})$, the amount of oil phase $(15 \%-25 \%, \mathrm{w} / \mathrm{w})$, surfactant $(37.5 \%-75 \%, \mathrm{w} / \mathrm{w})$ and cosurfactant $(15 \%-42.5 \%, \mathrm{w} / \mathrm{w})$ were screened and named as formulation 01-12. The thermodynamic and self-nanoemulsifying properties of these formulations were assessed and summarized (Table 1).

The formulations have passed the stress tests of centrifugation, heating-cooling cycle and freeze-thaw cycle. This showed the selected formulations (F01-12) were thermodynamically stable systems with no phase separation, creaming or cracking.

When infinite dilution is done to nanoemulsion formulation, there is a possibility of it to phase separately, leading to precipitation of a poorly soluble drug since nanoemulsions are formed at a particular concentration of oil, surfactant, cosurfactant, and water. ${ }^{42}$ We used distilled water and $0.1 \mathrm{~N}$ $\mathrm{HCl}$ as a dispersion medium because it is well reported that there is no significant difference in the nanoemulsions prepared using nonionic surfactants, dispersed in water or simulated gastric or intestinal fluids. ${ }^{42,43}$ When the formulation is diluted to 500 times and the amount of oil increases to $25 \%(\mathrm{~W} / \mathrm{W})$, the emulsification time was extended and the emulsified solution appears milky or slightly oil dropletslooking. The emulsification result of grade $\mathrm{C}$ or $\mathrm{D}$ was not selected. The formulations (F02, F05, F08 and F11) were chosen for self-nanoemulsifying characterization, in vitro dissolution and in vivo intestinal permeability study.

\section{Characterization of the GKA-SNEDDS}

The selected formulations (F02, F05, F08 and F11) were subjected for characteristic assessments, specifically emulsification time, droplet size, polydispersity index, zeta potential, and drug entrapment efficiency. The mean emulsification time was increased from $41.17 \pm 2.93 \mathrm{sec}$ to $54.23 \pm 2.51 \mathrm{sec}$, revealing that the emulsification time slightly increased with the increased concentration of surfactant in the formulation. Compared with the other three formulations and it was observed that the mean droplet size of the $\mathrm{F} 08$ formulation was $94.58 \mathrm{~nm} \pm 0.86$ with $\mathrm{PDI}<0.15$, a higher negative average zeta potential $(-14.56 \pm 1.64 \mathrm{mV})$ and a higher entrapment efficiency $(91.73 \% \pm 3.44)$. The 
Table 4 In vitro Characterization of GKA-SNEDSS (Mean \pm SD, $n=3$ )

\begin{tabular}{|l|l|l|l|l|l|}
\hline $\begin{array}{l}\text { Formulation } \\
\text { Code }\end{array}$ & $\begin{array}{l}\text { Emulsification Time } \\
\mathbf{( S e c )}\end{array}$ & $\begin{array}{l}\text { Droplet Size } \\
\mathbf{( n m )}\end{array}$ & $\begin{array}{l}\text { Polydispersity Index } \\
\text { (PDI) }\end{array}$ & $\begin{array}{l}\text { Zeta Potential } \\
(\mathbf{m V})\end{array}$ & $\begin{array}{l}\text { Entrapment } \\
\text { Efficiency }\end{array}$ \\
\hline F02 & $41.17 \pm 2.93$ & $127.08 \pm 1.77$ & $0.18 \pm 0.03$ & $-13.36 \pm 0.73$ & $76.90 \pm 2.86$ \\
F05 & $43.37 \pm 2.57$ & $101.24 \pm 1.85$ & $0.16 \pm 0.01$ & $-12.73 \pm 1.61$ & $83.75 \pm 3.31$ \\
F08 & $45.19 \pm 2.62$ & $94.58 \pm 0.86$ & $0.14 \pm 0.01$ & $-14.56 \pm 1.64$ & $91.73 \pm 3.44$ \\
FII & $54.23 \pm 2.51$ & $98.43 \pm 0.81$ & $0.27 \pm 0.02$ & $-13.63 \pm 1.30$ & $86.12 \pm 2.59$ \\
\hline
\end{tabular}

other formulations (F02, F05 and F11) have also shown their droplet size less than $150 \mathrm{~nm}$, PDI less than 0.30, and with zeta potentials around $-13 \mathrm{mV}$ (Table 4). The entrapment efficiency ( $\%$ ) for GKA was found to be in the range of 76-91\%, while the F08 formulation has shown higher entrapment efficiency. The results showed that when the Maisine CC content was 20\% (w/w), the percentage of Labrasol ALF was increased and the emulsification time was prolonged, whereas the droplet size was reduced. Since Labrasol ALF is a non-ionic surfactant and does not contribute much to zeta potential, the results of the formulations zeta potential were not significant $(p>0.05)$.

TEM images (Figure 1D) show the spherical nature of nano-emulsions with observed particle sizes less than 200 $\mathrm{nm}$ in each image. The morphology of the four formulations showed that the droplets of diluted GKA-SNEDDS were almost in spherical shape with smooth surface. Furthermore, no sign of drug precipitation was yet observed, indicating the physical stability of the formed nanoemulsion.

\section{In vitro Drug Release}

In vitro release studies were conducted to obtain insight into the release behavior of GKA-SNEDDS and GKAsuspension. As shown in Figure $2 \mathrm{~A}$ and $\mathrm{B}$, the cumulative dissolution of GKA-suspension in $\mathrm{pH} 1.2$ and $\mathrm{pH} 6.8$ dissolution media within $36 \mathrm{~h}$ was only about $10 \%$, verifying its poor aqueous solubility. However, the amount of GKA released from the four formulations (F02, F05, F08, and F11) was about $50 \%$ within $36 \mathrm{~h}$. The release profile of these formulations shows a rapid release followed by a steady phase, indicating a faster release rate and a higher cumulative dissolution rate compared to the GKAsuspension. According to the Noyes-Whitney equation $\left(\mathrm{dC} / \mathrm{dt}=\mathrm{k}_{\mathrm{D}} \mathrm{A}(\mathrm{Cs}-\mathrm{Ct})\right)$, the release of GKA is primarily influenced by its solubility because the fast release of GKA from SNEDDS is independent of the GKA-SNEDDS droplet size. By loading the drug into micelles or nanoemulsion particle sizes, SNEDDS could improve the solubility of GKA. ${ }^{44,45}$ Therefore, these results indicated that the greater availability of dissolved GKA from the SNEDDS formulation may result in better absorption and bioavailability. ${ }^{46}$

\section{Intestinal Permeability Study}

The intestinal permeability of GKA was evaluated in Male Sprague Dawley rats. The experimental results (Figure 2C) indicated that the effective permeability coefficient $\left(\mathrm{P}_{\text {eff }}\right)$ of GKA-suspension in the duodenum was $1.62 \times 10^{-4} \mathrm{~cm} / \mathrm{s}$, which was 1.38 times than that in the jejunum $\left(1.17 \times 10^{-4}\right.$ $\mathrm{cm} / \mathrm{s}$ ), demonstrating that GKA was primarily absorbed in the duodenum. ${ }^{29}$ Moreover, the $\mathrm{P}_{\mathrm{eff}}$ of GKA-SNEDDS formulation in the duodenum was also higher than that in the jejunum, indicating that GKA loaded in SNEDDS did not exert any influence on GKA intestinal absorption which is site dependent. The duodenal $\mathrm{P}_{\text {eff }}$ of the F02, F05, F08 and F11 formulations were $1.2(p<0.05), 1.4(p<0.01), 2.1(p<$ $0.01)$ and $1.9(p<0.01)$ times than that of GKA-suspension, respectively, indicating that GKA permeability can be significantly improved by using these four SNEDDS formulations. Reasonably, these results are likely attributed to lymphatic transport of the drug through the triglyceride core of the chylomicron, which is the primary lymphatic transport mechanism of insoluble drugs through lipid carriers (such as SNEDDS). ${ }^{47}$

\section{In vivo Pharmacokinetic Study}

The pharmacokinetic profile of the optimized GKASNEDDS (F08) was evaluated to analyze GKA in rat plasma after oral administration. The main objective of this study was to correlate the solubility and intestinal permeability of GKA with the enhancement of its oral bioavailability. The mean plasma concentration-time curves of GKA-suspension and the GKA-SNEDDS (F08) were presented (Figure 2D), and their pharmacokinetic parameters were listed (Table 5). As the results shown, the $\mathrm{C}_{\max }$ value of GKA from SNEDDS was significantly $(p<0.01)$ enhanced over 4.34 -fold than that of GKA-suspension, when the $\mathrm{AUC}_{0-24}$ of GKA also significantly increased by $353.28 \%$ (from $26.31 \pm 6.78$ to 92.95 
A

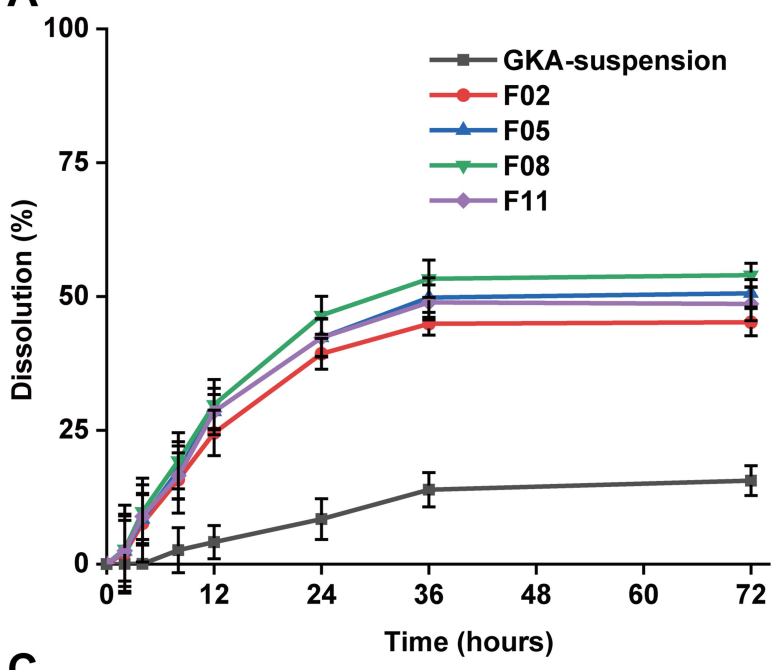

C

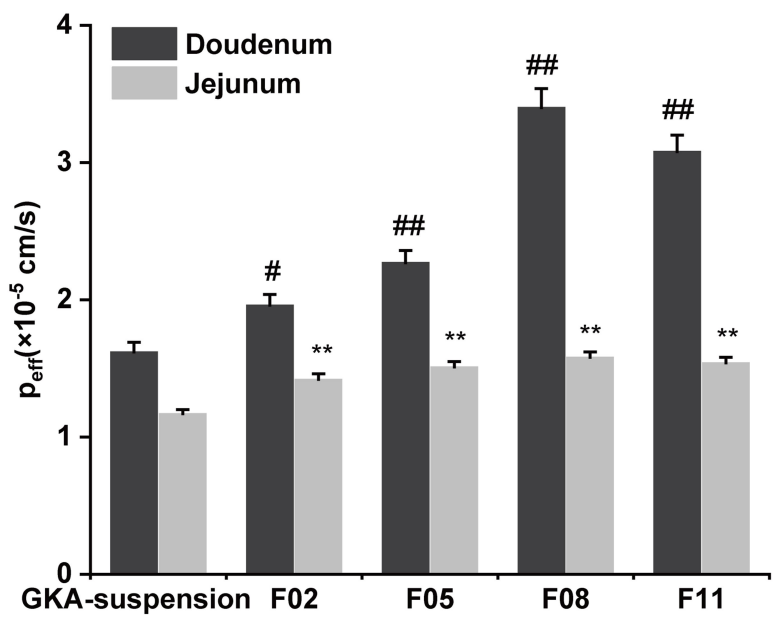

B

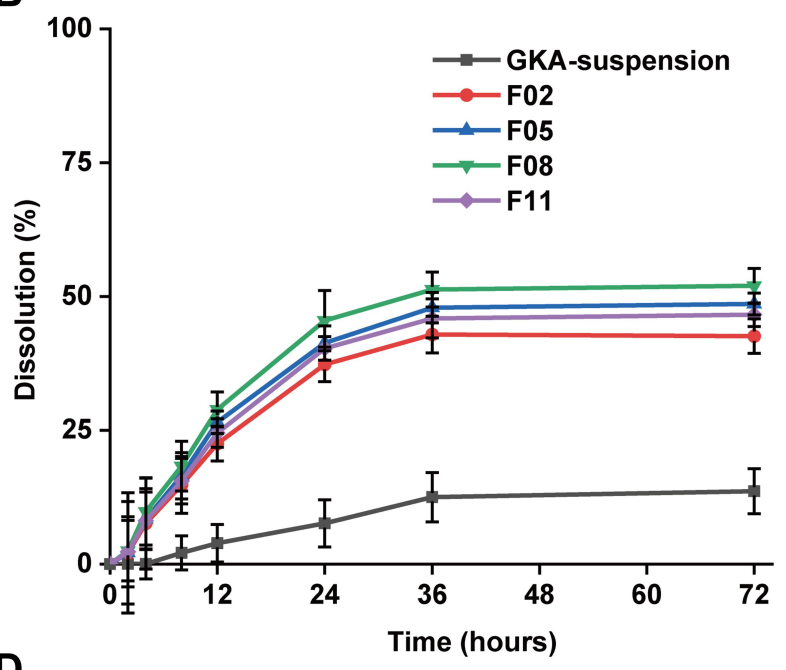

D

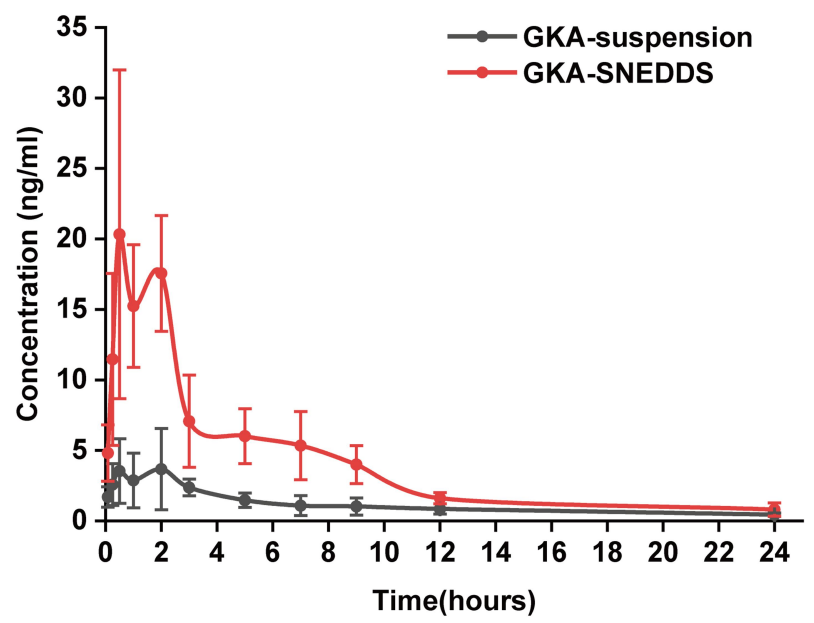

Figure 2 Dissolution profiles of GKA-SNEDDS and GKA-suspension in (A) Simulated gastric fluid (pH 1.2). (B) Simulated intestinal fluid (pH 6.8). (C) The effective permeability coefficient $\left(P_{\text {eff }}\right)$ of GKA-SNEDDS in rats' duodenum and jejunum by single-pass intestinal perfusion model. Each value represents the mean \pm SD ( $n=3$ ). ${ }^{\#} p<$ 0.05 and ${ }^{\#} p<0.01$ as compared to GKA- suspension group in duodenum, ${ }^{* *} p<0.01$ as compared to GKA-suspension group in jejunum. (D) Plasma concentration-time profiles of rats after oral administration of GKA-SNEDDS and GKA-suspension.

$\pm 22.89)$ in the SNEDDS-treated group as compared to the GKA-suspension group. The $\mathrm{T}_{\max }$ of GKA decreased from $1.83 \pm 1.12 \mathrm{~h}$ to $1.17 \pm 0.68 \mathrm{~h}$, indicating that the GKA

Table 5 Pharmacokinetic Parameters of GKA After Oral Administration of GKA-SNEDDS and GKA-Suspension

\begin{tabular}{|l|l|l|}
\hline Parameters & GKA-Suspension & GKA-SNEDDS \\
\hline $\mathrm{C}_{\max }(\mathrm{ng} / \mathrm{mL})$ & $5.23 \pm 2.14$ & $24.33 \pm 9.33^{* *}$ \\
$\mathrm{~T}_{\max }(\mathrm{h})$ & $1.83 \pm 1.12$ & $1.17 \pm 0.68$ \\
$\mathrm{AUC}_{0-24}(\mathrm{ng} \mathrm{h} / \mathrm{mL})$ & $26.31 \pm 6.78$ & $92.95 \pm 22.89 * *$ \\
$\mathrm{AUC}_{0-\infty}(\mathrm{ng} \cdot \mathrm{h} / \mathrm{mL})$ & $30.98 \pm 9.65$ & $100.41 \pm 20.31$ \\
$\mathrm{t}_{1 / 2}(\mathrm{~h})$ & $7.66 \pm 4.66$ & $3.62 \pm 1.37$ \\
$\mathrm{~F}(\%)$ & - & 353.28 \\
\hline
\end{tabular}

Notes: Data are expressed as mean $\pm S D(n=6), * * p<0.001$ as compared to GKA-suspension-treated group after oral administration, respectively

Abbreviations: $T_{\max }$, the time of peak concentration; $C_{\max }$, the Peak of maximum concentration; $\mathrm{AUC}_{0-24}$, the area under the concentration-time profile curve of up to $24 \mathrm{~h}$; $\mathrm{F}$, the relative bioavailability. absorption was accelerated by SNEDDS. Additionally, compared with GKA-suspension, the $t_{1 / 2}$ value of GKA in blood was shortened by SNEDDS, which showed that SNEDDS may slightly accelerate the metabolism of GKA. The pharmacokinetic study in rats indicated that SNEDDS could significantly improve the bioavailability of GKA.

\section{The Therapeutic Effect of GKA-SNEDDS GKA-SNEDDS Reduces Macroscopic Damage}

The progress of establishment and administration of AOM/ DSS model is shown in Figure 3A. The body weight of mice in the model and GKA-treated groups (GKA-suspension, and GKA-SNEDDS) decreased substantially during each circle of DSS and moderately retrieved after DSS treatment was finished (Figure 3B). From the first circle of DSS, the animal body weights in both the model and GKA-treated 
A

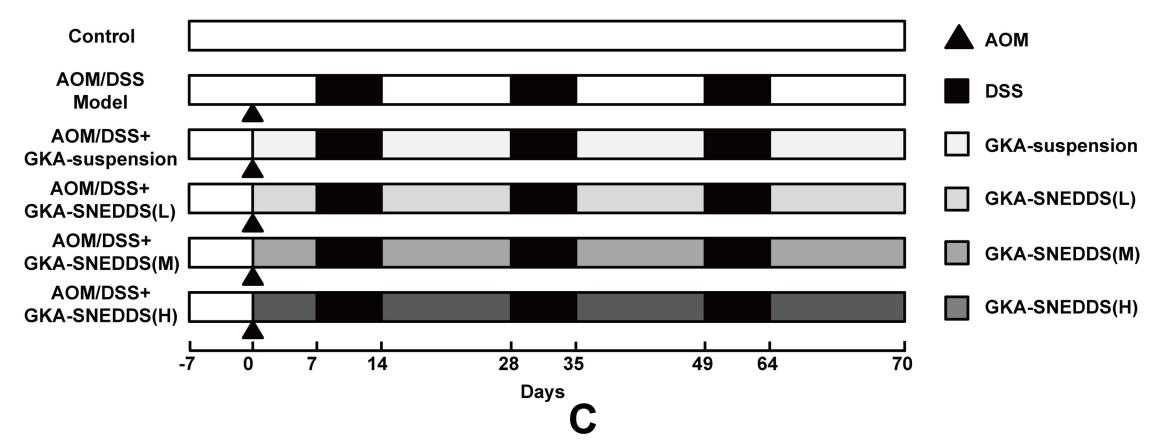

B
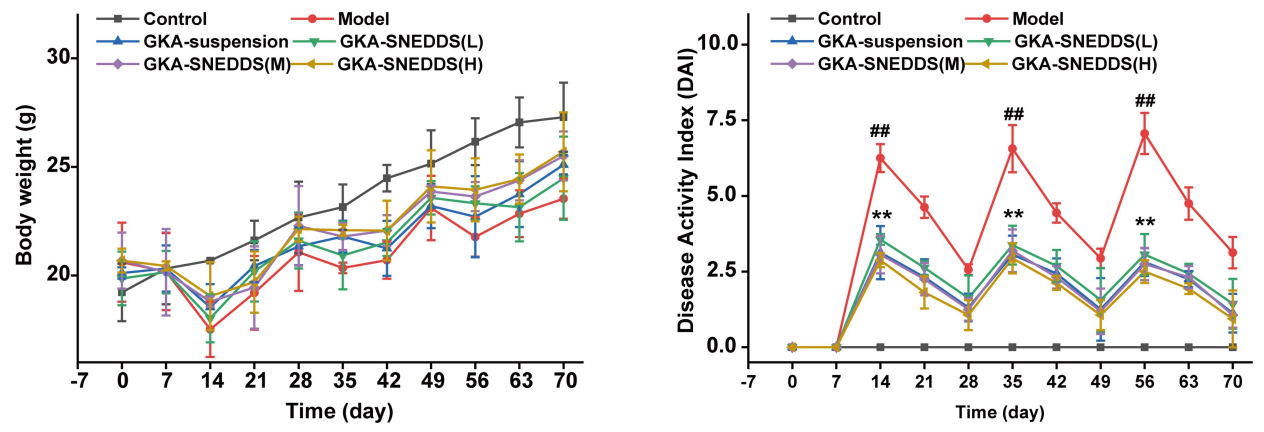

D

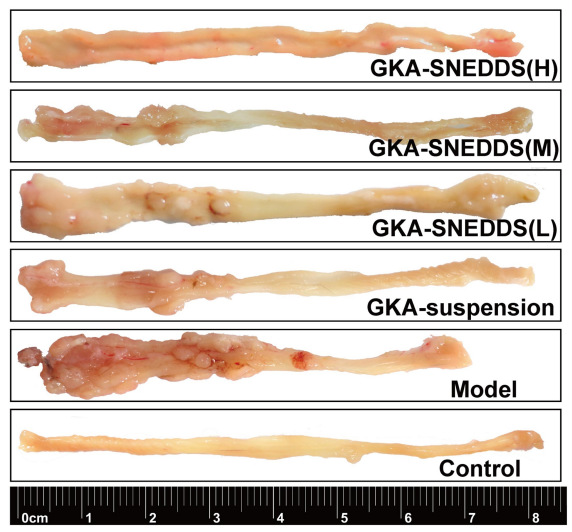

E

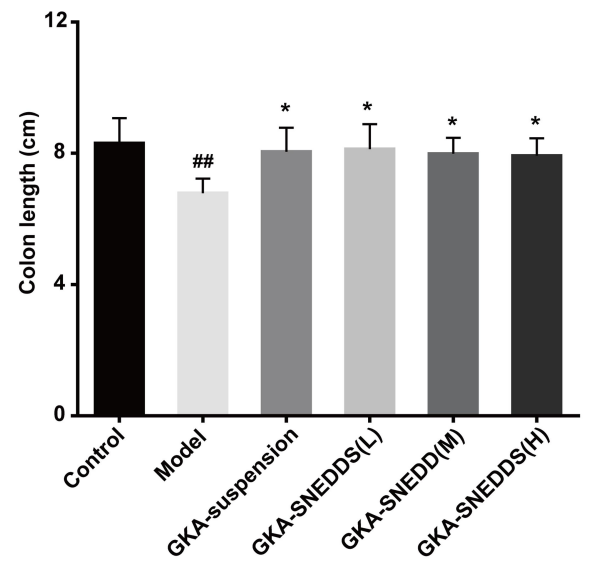

F

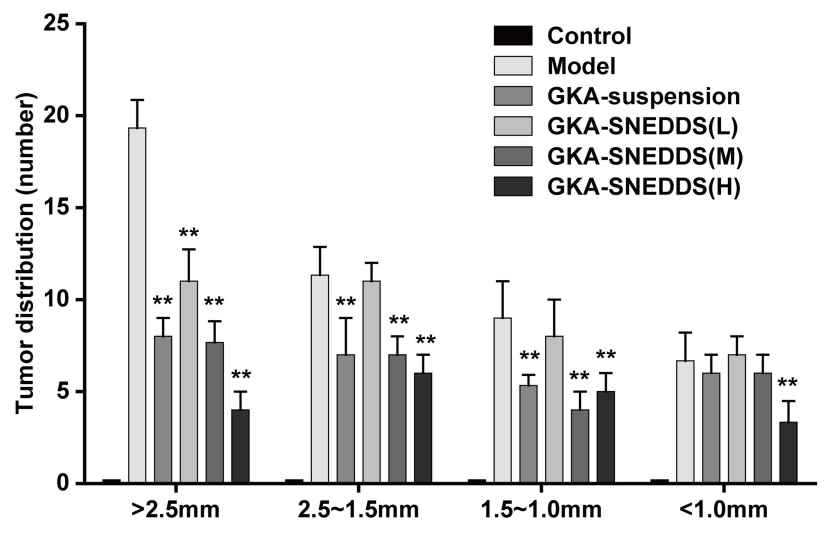

Figure 3 GKA-SNEDSS significantly prevented initiation and progression of CAC. (A) AOM/DSS model establishment and administration. (B) Mice body weight changes. (C) Disease activity index. (D) Representative macroscopic features of colon length and tumor growth. (E) Colon lengths. (F) Tumor multiplicity changes in the colon. The results were expressed as mean \pm SD. ${ }^{\# \#} p<0.01$ compared with the control group, $*_{p}<0.05$ and $*^{*} p<0.01$ compared with the model group. 
group were significantly lower than that in the control group, which showed a slowly daily increase during the whole period of experiment. However, the body weight loss was significantly attenuated in the GKA-SNEDDS (H)-treated group and GKA-SNEDDS (M)-treated group.

DAI score is a common parameter that helps to evaluate the severity of colonic inflammation, that is saying the higher DAI score is, the more serious colitis injury is. ${ }^{48}$ After DSS administration, AOM/DSS-treated mice showed signs of weight loss, diarrhea and bloody stool. Thus, DAI score in AOM/DSS-treated mice group increased rapidly compared with the control group ( $p<$ 0.01). However, DAI scores of the GKA-treated groups were significantly lower than that of the control group and presented a dose-dependent manner $(p<0.01)$. Furthermore, while comparing the GKA-suspensiontreated group and GKA-SNEDDS (M)-treated group, the result showed no statistically significant difference $(p>$ 0.05), whereas the DAI score of the GKA-SNEDDS (H)treated group was significantly lower than that of the GKA-suspension-treated group $(p<0.01)$. These results indicated that GKA-SNEDDS treatments could effectively alleviate colonic mucosal injuries of mice treated with AOM/DSS, which include edema, hyperemia, intestinal wall thickening, mucosal erosion and ulcer (Figure 3C).

The colon length and tumor genesis in CAC mice were visually reflected in Figure 3D-F. No tumor area was observed in the control group. The model group was observed with obvious atrophy of the colon, severe necrosis of distal colon tissue and the significantly shortened colon length compared with the control group $(p<0.01$, Figure $3 \mathrm{E}$ ). Besides, tumor numbers and tumors burden both significantly increased in comparison with the control group ( $p<0.01$, Figure 3F). GKA-treated mice were found to possess less tumor burden and shorter intestinal lengths compared with the AOM/DSS-treated group. Moreover, administrations of the GKA-SNEDDS significantly decreased the number of tumors in a dose-dependent manner. The aforementioned results suggested that GKASNEDDS can efficiently suppress the tumorigenesis.

\section{Effects of GKA-SNEDDS on Histological Alternation}

$H \& E$ staining and the histological scores showed that the control group exhibited intact mucosa, perfect submucosa, and uninjured colonic mucosa and orderly arranged glandular cells. In addition, no inflammatory cell infiltration in the normal crypts was observed from the control group (Figure 4). While the AOM/DSS-treated group showed a number of inflammatory features, including infiltration of inflammatory cells in the mucosa or lamina propria, distortion or disappearance of crypt structure and loss of enterocyte, which led to a low microscopic score $(p<0.01)$. In contrast, obvious recoveries of crypts architecture epithelium as well as reduction of histological inflammation were observed in the GKA-SNEDDS and GKA-suspension groups. Moreover, deteriorating pathologies were also observed to be alleviated in the GKA-SNEDDS (H)treated group $(22.5 \mathrm{mg} / \mathrm{kg})(p<0.01)$. GKA-suspensiontreated $(22.5 \mathrm{mg} / \mathrm{kg})$ group exhibited a similar therapeutic effect to GKA-SNEDDS (M)-treated group $(p>0.05)$.
A

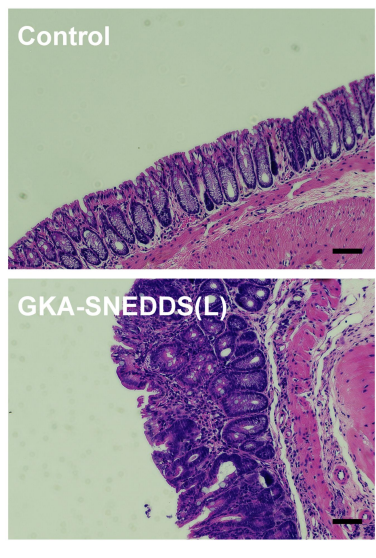

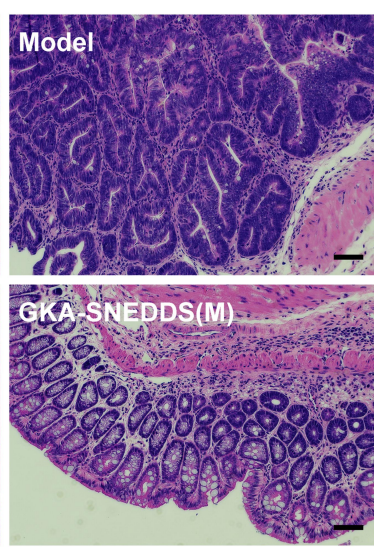

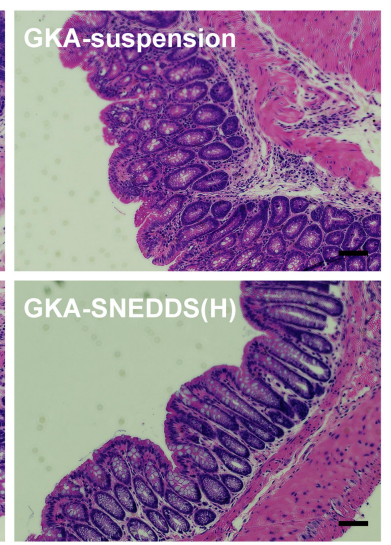

B

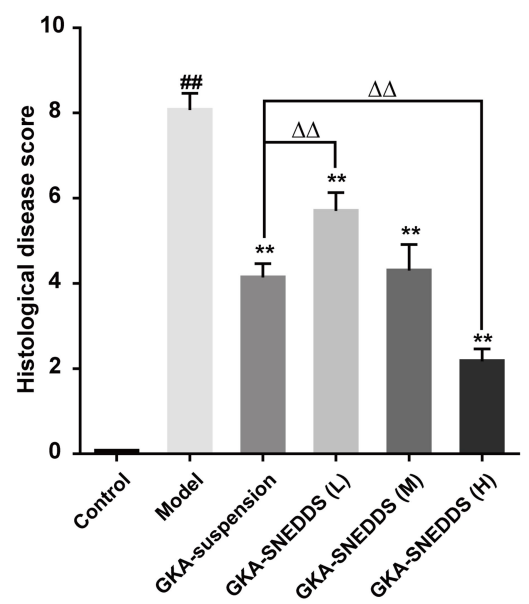

Figure 4 (A) Representative H\&E staining histological sections showing inflammatory changes in the colon. Scales bar, I00 $\mu m$. (B) Histological disease score. The results were expressed as mean \pm SD. ${ }^{\#} p<0.01$ compared with the control group, ${ }^{* *} p<0.0$ I compared with the model group, ${ }^{\Delta \Delta} p<0.01$ compared with the GKA-suspensiontreated group. 
These results suggested that GKA has observable therapeutic effects against CAC induced by AOM/DSS with a doseand formulation-dependent manner.

\section{Effects of GKA-SNEDDS on Inflammatory Cytokines} Inflammatory and immunity cytokines play a pivotal role in a wide variety of human cancers with CAC included. ${ }^{36,49}$ Compared with the control group, the levels of pro-inflammatory cytokines (IL-1, IL-6, IL-8, TNF- $\alpha$ ) in the AOM/DSS-treated group were significantly increased (Figure 5A-D; $\mathrm{P}<0.01$ ). As the result showed, administration of GKA could inhibit the levels of these pro-inflammatory cytokines significantly. The antiinflammatory cytokines including IL-10 and INF- $\gamma$ were decreased to a lower level after AOM/DSS exposure, while anti-inflammatory cytokines recovered significantly after GKA-SNEDDS (M, H) and GKA-suspension treatment (Figure 5E and F; $p<0.01$ ). Moreover, compared with GKA-suspension, GKA-SNEDDS $(\mathrm{H})$ performed better in inhibiting pro-inflammatory cytokines and promoting anti-inflammatory cytokines $(p<0.05)$. Furthermore, GKA-suspension had similar effects with GKA-SNEDDS (M) in the attenuation of inflammatory cytokines.

\section{GKA-SNEDDS Inhibits Cell Proliferation and Induces Apoptosis}

Colonic tumorigenesis is associated with intestinal epithelial homeostasis, which is controlled by the balance between proliferation and apoptosis of mucosal cells. ${ }^{50}$ The intestinal homeostasis of mice treated with GKA-suspension or GKASNEDDS were compared. Additionally, cell proliferation was detected by Ki-67 and PCNA staining. Besides, DNA fragments in colon tissue were detected by TUNEL staining. We found that compared with AOM/DSS mice, tissue from GKA-treated mice displayed a decrease in the number of Ki-67 (Figure 6A and D) and PCNA positive cells
A

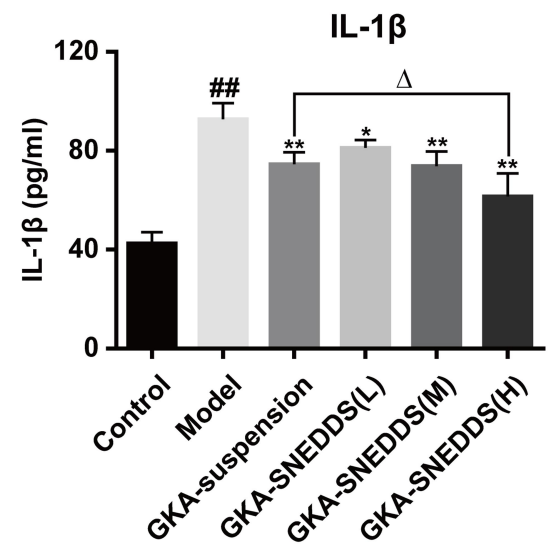

D

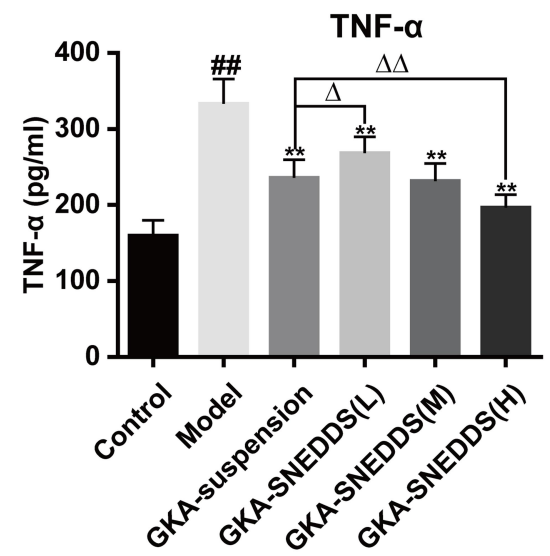

B

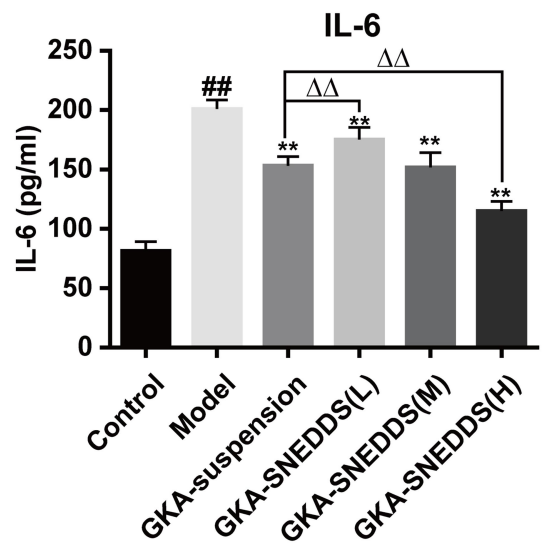

E

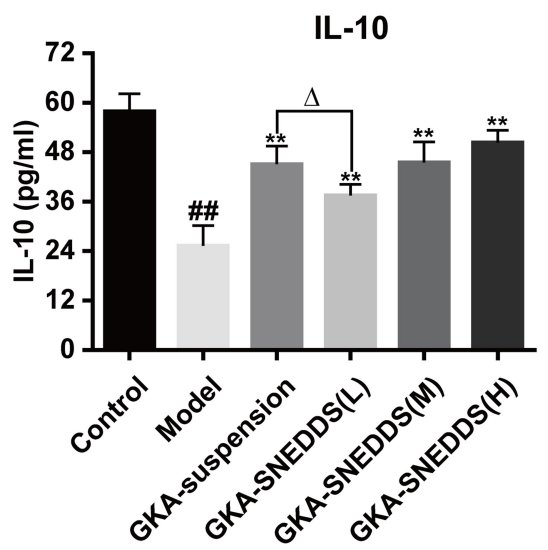

C

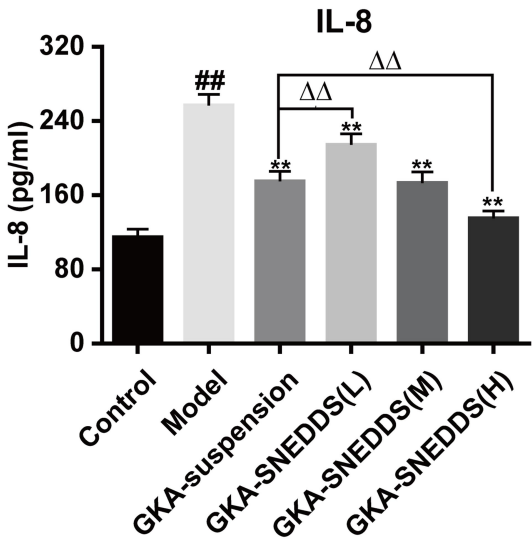

$\mathbf{F}$

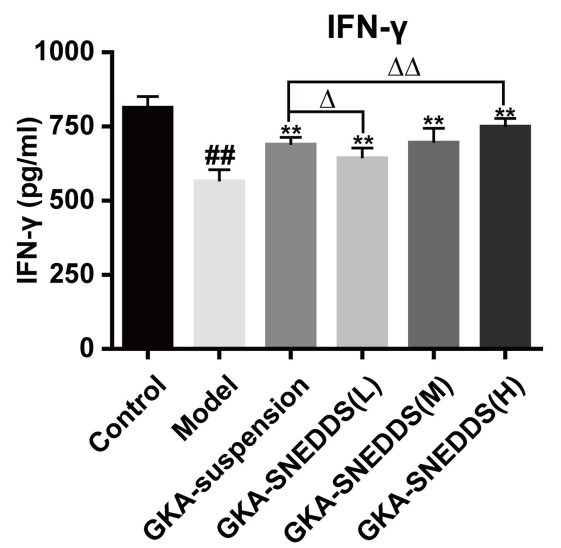

Figure 5 Effects of GKA-SNEDDS on inflammatory cytokines. Data are presented as mean \pm SD $(n=8) .{ }^{\#} p<0.01$ compared with the control group, ${ }^{*} p<0.05$ and ${ }^{* *} p<$ 0.01 compared with the model group, ${ }^{\Delta} p<0.05$ and ${ }^{\Delta \Delta} p<0.01$ compared with the GKA-suspension-treated group. 

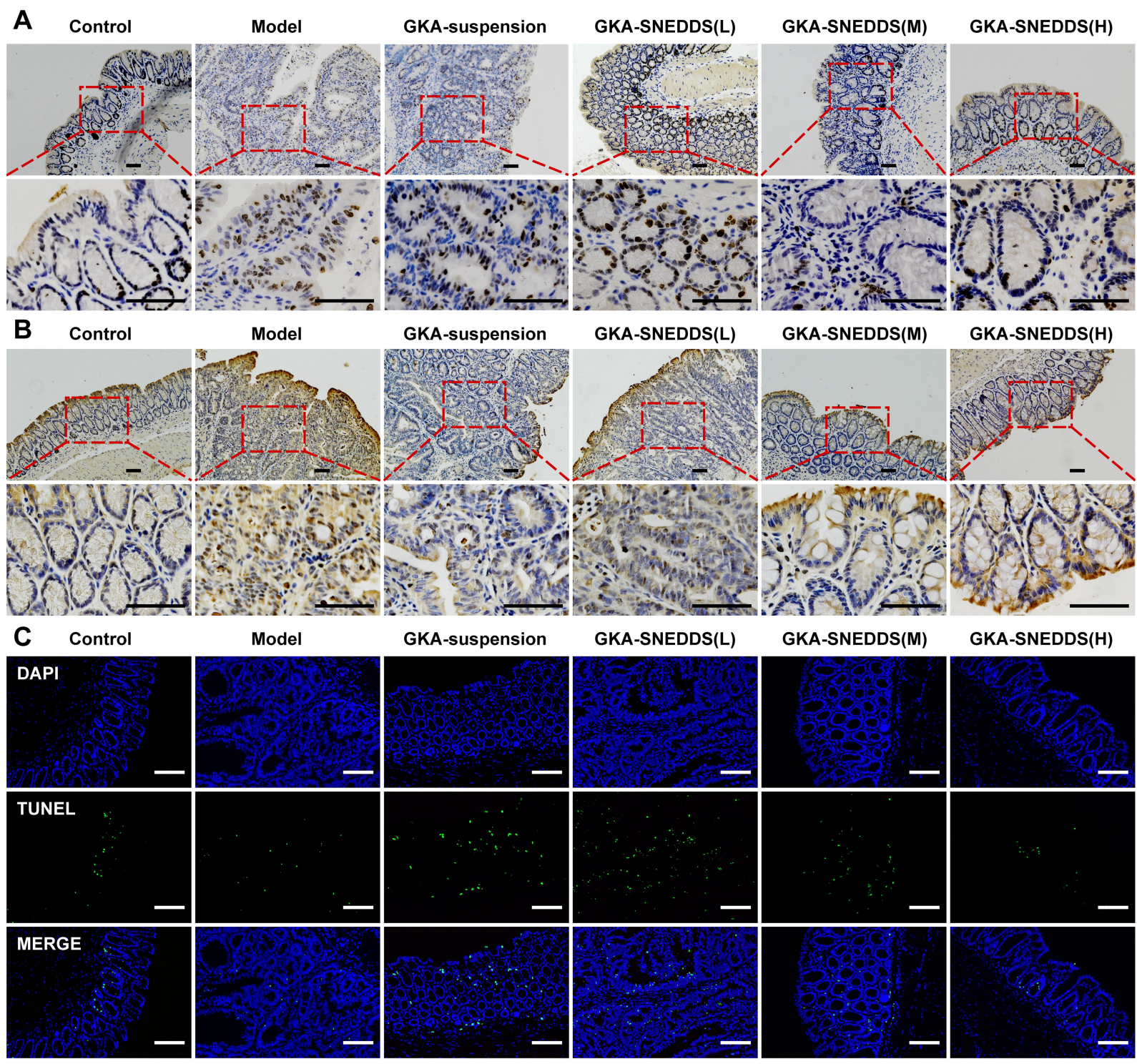

GKA-SNEDDS(H)
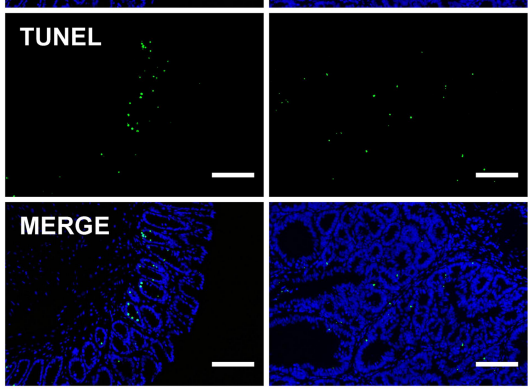

D

E
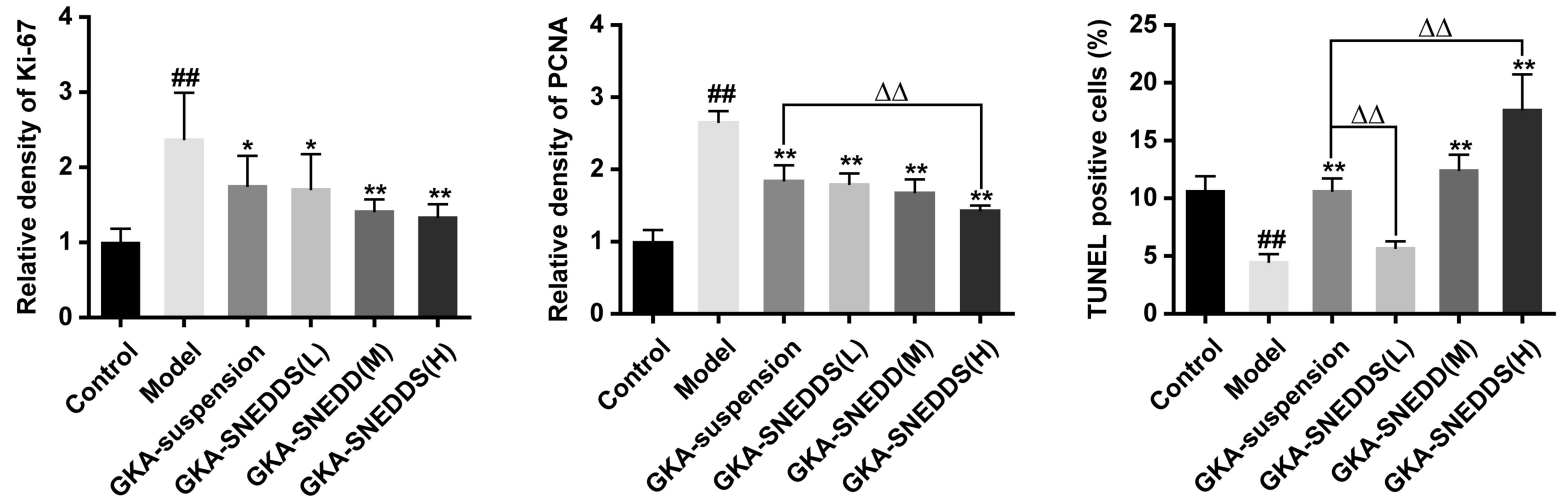

Figure 6 Administration of GKA inhibits cell proliferation and induces apoptosis in the colon. (A) Cell proliferation was measured via Ki-67 staining of colon sections from

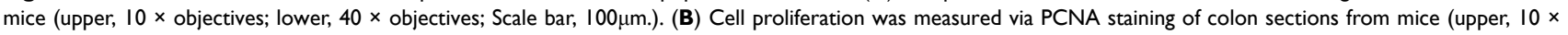

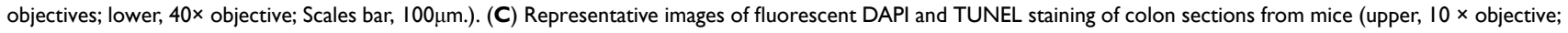

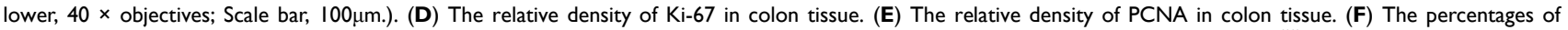
apoptotic cells in the colon tissue were quantified and normalized versus the number of nuclei. Data are presented as mean $\pm S D(n=8)$. ${ }^{\#} p<0.01$ compared with the control group, ${ }^{*} p<0.05$ and ${ }^{* *} p<0.01$ compared with the model group, ${ }^{\Delta \Delta} p<0.01$ compared with the GKA-suspension-treated group. 
(Figure 6B and E). In addition, the average TUNEL labeling indices of colon in mice treated only with AOM/DSS was significantly lower than that of the control group and the administration of GKA-SNDSS significantly increased the number of TUNEL-positive cells compared with AOM/ DSS-treated mice (Figure 6C and F). As shown by the above results, GKA-SNEDDS exhibited promising properties on inhibiting cell proliferation and inducing cell apoptosis in colon tissues with a dose-dependent manner.

\section{Discussion}

GKA is one of the most renowned flavonoids from the phenolic compounds with various promising pharmacological properties. Our previous studies have shown that GKA treatment significantly ameliorates the tumorigenesis symptoms in $\mathrm{APC}^{\mathrm{Min} /+}$ mice model. ${ }^{13,51}$ However, oral administration of GKA faces the limitations of it having low aqueous solubility and low oral bioavailability, which greatly restrict its clinical application in medicine. Therefore, for the further application of GKA, it is necessary to develop a novel formulation using advanced strategies to improve its aqueous solubility and bioavailability, as well as to minimize toxicity and side effects.

In recent years, nanoparticle-based drug delivery systems have become a promising strategy which has been widely used in the treatment of inflammatory bowel disease. ${ }^{52-54}$ SNEDDS technology is a lipid-based drug delivery system that has attracted the attention of the pharmaceutical industry and is considered to be a promising drug carrier for improving the oral bioavailability of poorly soluble drugs. ${ }^{55}$ To date, many commercial SNEDDS drugs have been approved by FDA, such as kaletra $^{\circledR}$ (Ritonavir/Lopinavir), Aptivus ${ }^{\circledR}$ (Tipranavir), Sandimmune $^{\circledR}$ (cyclosporine). ${ }^{17,56}$ Given the advantages of the SNEDDS technology and its application in medicine, this study used it to increase the solubility and enhance the bioavailability of GKA.

Given that both excellent emulsifying ability and low adverse reactions are considered as vital criteria for developing the best formulations of GKA for oral administration, we preliminarily optimized the formulations by using various kinds of oils, surfactants, and cosurfactants. In the solubility study, GKA was found to exhibit maximum solubility in Maisine CC. Our result also indicated that Maisine CC resulted in the smallest droplet size and PDI compared with other selected oils. Maisine CC is winterized oil composed of long-chain mono-, di-, and triglycerides for lipid-based formulations and is commonly applied not only to solubilize poorly water-soluble lipophilic APIs but to increase their oral bioavailabilities at the same time. ${ }^{57,58}$ This property enhances chyle particle production as well as lymphatic transport of drug and avoids drug degradation by first-pass hepatic metabolism, by which reasons the bioavailability of the drug can be improved. ${ }^{47,59}$ Hence, for the purposes of achieving optimum drug loading, forming the smallest particle sizes and improving lymphatic transport of GKA, Maisine CC was selected as the oil phase in GKA-SNEDDS.

For emulsifying the oil spontaneously to eventually form SNEDDS, the surfactant is preferred to be nonionic (less toxic than ionic) and has an appropriate hydrophilelipophile balance (HLB) value (HLB $\geq 12$ ) in the optimized formulation. ${ }^{60}$ Labrasol ALF is a safe surfactant with short formation time of self-emulsification, of which the HLB value is favorable to form the smallest globule size nanoemulsion. ${ }^{61}$ The other nonionic surfactants, such as Kolliphor HS 15 (HLB=12-14), Tween $80(\mathrm{HLB}=15)$ and CremophorRH40 (HLB=14-16) are extensively used to improve the dissolution and delivery of drugs. ${ }^{62}$ Among the various selected surfactants, Labrasol ALF was selected as the surfactant in formulating SNEDDS, as it exhibited high solubility of GKA and the smallest droplet size.

The cosurfactant is one of the essential ingredients used in the SNEDDS formulations, which is capable of reducing interfacial tension, increasing the drug loading, adjusting self-nano-emulsification time and particle sizes as well as expanding self-nanoemulsification areas in the pseudo-ternary diagrams. ${ }^{18,63}$ Transcutol HP, consisting of highly purified diethylene glycol monoethyl ether which has efficiency in spontaneous nanoemulsion, is a kind of regularly employed cosurfactant in nano-formulation. ${ }^{64-66}$ In comparison to the other cosurfactants, Transcutol HP exhibited the best dissolving capacity for GKA $(4.57 \mathrm{mg} / \mathrm{mL})$.

According to the result thermodynamic stability experiment and emulsification efficiency experiment, four candidate formulations (F02, F05, F08 and F11) were firstly screened and then evaluated by the self-nanoemulsification time, droplet size, entrapment efficiency, drug release, and intestinal permeability. The optimized formulation (F08) was selected: Maisine CC, Labrasol ALF, and Transcutol HP at a weight ratio of 20:60:20 (w/w/w). In vivo intestinal permeability results showed that Maisine CC significantly increased the solubility of GKA and improved the transport in the lymphatic system, whereas Labrasol ALF 
inhibited the efflux pump which further contributed to the enhanced permeability of GKA. ${ }^{67}$ Compared with other candidate formulations, F08 has better permeability, indicating that the release and absorption of GKA from SNEDDS may be determined by the physical characteristics of each formulation, such as emulsification efficacy, particle size and entrapment efficiency.

The pharmacokinetic profile of GKA-SNEDDS (F08) presented significantly enhanced relative bioavailability of GKA in comparison with GKA-suspension. Also, there was an obvious bimodal concentration-time curve. However, this may not only be triggered by GKA entering hepatic circulation but could also be due to the partial gastric digestion. The bimodal profile in this study was characterized by a rapid initial release of the drug from the lipid-based GKA-SNEDDS followed by a constant release rate, after which a second-time fast release of drug was observed again at the terminal phase. Bimodal release profiles of a GKA's structurally similar analogue, specifically apigenin, were obtained by a previous study. ${ }^{68}$

The SNEDDS system has several possible mechanisms regarding improving the bioavailability of drugs, including drug solubilization in intestinal fluid, modification of transport mechanisms in enterocytes and modification of drug distribution into systemic circulation (portal bloodstream vs lymphatic system). ${ }^{6-71}$ Our previous result indicated that the transport mechanism of GKA is via passive diffusion and active multidrug resistance proteinmediated efflux through the enterocytes' membrane. ${ }^{29,72}$ Therefore, the intestinal permeability and bioavailability of GKA can be significantly improved through SNEDDS technology. The inferred mechanisms are that, on the one hand, not only it improved the solubility and lymphatic transport of GKA, but it helped with forming smaller selfnano emulsified particle size; on the other hand, it promoted GKA absorption by inhibiting the relative efflux pump.

In this study, we evaluated the CAC therapeutic effect of GKA-SNEDDS (F08) in parallel to GKA-suspension. The AOM/DSS-induced CAC model was first constructed followed by the assessment of the clinical symptoms, namely body weight change, DAI, colon length, tumor genesis and histological alterations. As the result, compared with the control group, it was found that the model group exhibited significant body weight loss with a higher DAI score and induced tumor genesis. However, GKASNEDDS treatment exhibited excellent therapeutic effects, to be more specific, it not only attenuated the loss of body weight, but decreased DAI score as well as reduced tumor amount in a dose-dependent manner. Moreover, the beneficial effect of GKA-SNEDDS was further confirmed by histological analysis. Colonic mucosa damage and infiltration of inflammatory cells were significantly ameliorated by GKA-SNEDDS treatment, which indicated that GKASNEDDS had promising therapeutic effects compared with GKA-suspension. All these results suggested that the improved intestinal permeability and pharmacokinetic properties by SNEDDS might significantly contribute to the therapeutic effects of GKA against CAC.

$\mathrm{CAC}$ is a kind of malignant tumor with chronic inflammatory mucosa. In regard to inflammation, it is one of the most common potential carcinogens in the colon. ${ }^{73}$ Unbalanced release of cytokines easily leads to inflammation and intestinal mucosa damage. Moreover, it is widely acknowledged that various cytokines (such as IL-1 $\beta$, IL-6, IL-8, TNF- $\alpha$, IL-10 and INF- $\gamma$ ) are vital signals in the intestinal immune system. ${ }^{74}$ IL-1 $\beta$, IL-6, IL-8, and TNF- $\alpha$ are the key pro-inflammatory mediators that may cause intestinal mucosal impairment resulting in inflammation. ${ }^{75}$ IL-10 and INF- $\gamma$ are known as potent immunosuppressive and immunoregulatory factors that could effectively inhibit the synthesis of proinflammatory cytokine and the presentation of antigen, thus ultimately reduce the response of inflammation. ${ }^{76}$ In our study, GKA-SNEDDS significantly inhibited the production of AOM/DSS-induced IL-1 $\beta$, IL-6, IL-8, and TNF- $\alpha$, and wisely promoted the production of immuneregulatory mediators in a dose-dependent manner. Additionally, the anti-inflammatory effect of high dose GKA-SNEDDS was better than that of medium and low dose GKA-SNEDDS, let alone GKA-suspension. These results indicated that the effects of GKA-SNEDDS inhibiting tumor development and progression might be closely related to the enhancement of immune response and the reduction of gut inflammation.

Besides, cell proliferation in GKA-suspension and GKASNEDDS group was both examined by Ki-67 and PCNA staining. In addition, the apoptosis assessments of both groups were carried out by TUNEL staining. These results indicate that GKA-SNEDDS administration could significantly inhibit the formation of colon tumors through inducing the cell apoptosis in AOM/DSS-induced CAC mice model. In summary, the designed SNEDDS efficiently enhanced the applicability of GKA from improving oral absorption and anti-CAC specialty, as evidenced by in vitro characterization, in vivo pharmacokinetics and pharmacodynamics assessments. 


\section{Conclusion}

This is the first report on the GKA application for prevention and treatment of CAC. The GKA-SNEDDS formulations for oral administration against CAC were successfully developed and characterized. The representative SNEDDS formulated for GKA in the current study provide collective advantages, specifically superior selfemulsification efficiency with improved physical stability, increased solubility, enhanced intestinal permeability and elevated bioavailability. The present study demonstrates that GKA in SNEDDS possesses strong efficacy against $\mathrm{CAC}$ in $\mathrm{C} 57 \mathrm{BL} / 6 \mathrm{~J}$ Mice via regulating immune functions, inhibiting the production of inflammatory cytokines as well as suppressing tumor proliferation from promoting tumor cell apoptosis. Overall, SNEDDS with promising in vitro and in vivo characteristics could serve as a technical platform for the oral delivery of insoluble herbal drugs such as GKA.

\section{Acknowledgments}

This work was supported by the National Key R\&D Program of China (Grant Number: 2018YFC1707105), the Natural Science Foundation of Jiangsu Province (Grant Number: BK20131309) and the Funding of Double First-rate Discipline Innovation Team (Grant Number: CPU2018GF05\&CPU2018GY11).

\section{Disclosure}

Hua-Feng Yin is an employee of Jiangxi QingFeng Pharmaceutical Co., Ltd. The authors report no other potential conflicts of interest in this work.

\section{References}

1. Kuppusamy P, Yusoff MM, Maniam GP, Ichwan SJ, Soundharrajan I, Govindan N. Nutraceuticals as potential therapeutic agents for colon cancer: a review. Acta Pharm Sin B. 2014;4(3):173-181. doi:10.1016/ j.apsb.2014.04.002

2. Eisenstein M. Biology: a slow-motion epidemic. Nature (London). 2016;540(7634):S98-S99. doi:10.1038/540S98a

3. Shapiro JM, Subedi S, LeLeiko NS. Inflammatory bowel disease. Pediatr Rev. 2016;37(8):337-347. doi:10.1542/pir.2015-0110

4. Koliaraki V, Pallangyo CK, Greten FR, Kollias G. Mesenchymal cells in colon cancer. Gastroenterology. 2017;152(5):964-979. doi:10.1053/ j.gastro.2016.11.049

5. Schetter AJ, Heegaard NH, Harris CC. Inflammation and cancer: interweaving microRNA, free radical, cytokine and p53 pathways. Carcinogenesis. 2010;31(1):37-49. doi:10.1093/carcin/bgp272

6. Shastri S, Shinde T, Sohal SS, Gueven N, Eri R. Idebenone protects against acute murine colitis via antioxidant and anti-inflammatory mechanisms. Int J Mol Sci. 2020;21(2):484. doi:10.3390/ijms 21020484
7. Tian R, Liu X, Luo Y, et al. Apoptosis exerts a vital role in the treatment of colitis-associated cancer by herbal medicine. Front Pharmacol. 2020;11. doi:10.3389/fphar.2020.00438

8. Valledor A, Gao Y, Liu F, et al. Genkwanin inhibits proinflammatory mediators mainly through the regulation of miR-101/MKP-1/MAPK pathway in LPS-activated macrophages. PLoS One. 2014;9(5).

9. Kim AR, Zou YN, Park TH, et al. Active components from Artemisia iwayomogi displaying $\mathrm{ONOO}(-)$ scavenging activity. Phytother Res. 2004;18(1):1-7. doi:10.1002/ptr.1358

10. Nasr-Bouzaiene N, Sassi A, Bedoui A, Krifa M, Chekir-Ghedira L, Ghedira K. Immunomodulatory and cellular antioxidant activities of pure compounds from Teucrium ramosissimum Desf. Tumor Biol. 2016;37(6):7703-7712. doi:10.1007/s13277-015-4635-0

11. Lucarini R, Tozatti MG, Silva ML, et al. Antibacterial and anti-inflammatory activities of an extract, fractions, and compounds isolated from Gochnatia pulchra aerial parts. Braz J Med Biol Res. 2015;48(9):822-830. doi:10.1590/1414-431x20154410

12. Bao Y, Sun YW, Ji J, et al. Genkwanin ameliorates adjuvant-induced arthritis in rats through inhibiting JAK/STAT and NF-kappaB signaling pathways. Phytomedicine. 2019;63:153036. doi:10.1016/j.phymed. 2019.153036

13. Wang X, Song Z-J, He X, et al. Antitumor and immunomodulatory activity of genkwanin on colorectal cancer in the APC Min/+ mice. Int Immunopharmacol. 2015;29(2):701-707. doi:10.1016/j.intimp.20 15.09.006

14. Li Y, Hong J, Li H, et al. Genkwanin nanosuspensions: a novel and potential antitumor drug in breast carcinoma therapy. Drug Deliv. 2017;24(1):1491-1500. doi:10.1080/10717544.2017.1384519

15. Perez-Sanchez A, Borras-Linares I, Barrajon-Catalan E, et al. Evaluation of the intestinal permeability of rosemary (Rosmarinus officinalis L.) extract polyphenols and terpenoids in Caco-2 cell monolayers. PLoS One. 2017;12(2):e0172063. doi:10.1371/journal. pone. 0172063

16. Date AA, Desai N, Dixit R, Nagarsenker M. Self-nanoemulsifying drug delivery systems: formulation insights, applications and advances. Nanomedicine. 2010;5(10):1595-1616. doi:10.2217/nnm.10.126

17. Park H, Ha ES, Kim MS. Current status of supersaturable self-emulsifying drug delivery systems. Pharmaceutics. 2020;12 (4):365. doi:10.3390/pharmaceutics 12040365

18. Rehman FU, Shah KU, Shah SU, Khan IU, Khan GM, Khan A. From nanoemulsions to self-nanoemulsions, with recent advances in self-nanoemulsifying drug delivery systems (SNEDDS). Expert Opin Drug Deliv. 2017;14(11):1325-1340. doi:10.1080/17425247. 2016.1218462

19. Qiao J, Ji D, Sun S, et al. Oral bioavailability and lymphatic transport of pueraria flavone-loaded self-emulsifying drug-delivery systems containing sodium taurocholate in rats. Pharmaceutics. 2018;10 (3):147. doi:10.3390/pharmaceutics10030147

20. Khan AW, Kotta S, Ansari SH, Sharma RK, Ali J. Selfnanoemulsifying drug delivery system (SNEDDS) of the poorly water-soluble grapefruit flavonoid Naringenin: design, characterization, in vitro and in vivo evaluation. Drug Deliv. 2015;22 (4):552-561. doi:10.3109/10717544.2013.878003

21. Qian J, Meng H, Xin L, et al. Self-nanoemulsifying drug delivery systems of myricetin: formulation development, characterization, and in vitro and in vivo evaluation. Colloids Surf B Biointerfaces. 2017;160:101-109. doi:10.1016/j.colsurfb.2017.09.020

22. Ahmad G, El Sadda R, Botchkina G, Ojima I, Egan J, Amiji M. Nanoemulsion formulation of a novel taxoid DHA-SBT-1214 inhibits prostate cancer stem cell-induced tumor growth. Cancer Lett. 2017;406:71-80. doi:10.1016/j.canlet.2017.08.004

23. Angelova A, Garamus VM, Angelov B, Tian Z, Li Y, Zou A. Advances in structural design of lipid-based nanoparticle carriers for delivery of macromolecular drugs, phytochemicals and anti-tumor agents. Adv Colloid Interface Sci. 2017;249:331-345. doi:10.1016/j.cis.2017.04.006 
24. Shafiq S, Shakeel F, Talegaonkar S, Ahmad FJ, Khar RK, Ali M. Development and bioavailability assessment of ramipril nanoemulsion formulation. Eur J Pharm Biopharm. 2007;66(2):227-243. doi:10.1016/j.ejpb.2006.10.014

25. Akhtar N, Talegaonkar S, Khar RK, Jaggi M. Self-nanoemulsifying lipid carrier system for enhancement of oral bioavailability of etoposide by P-glycoprotein modulation: in vitro cell line and in vivo pharmacokinetic investigation. J Biomed Nanotechnol. 2013;9 (7):1216-1229. doi:10.1166/jbn.2013.1613

26. Shen J, Bi J, Tian H, et al. Preparation and evaluation of a self-nanoemulsifying drug delivery system loaded with Akebia saponin D-phospholipid complex. Int $J$ Nanomedicine. 2016;11:49 19-4929. doi:10.2147/IJN.S108765

27. Khoo S-M, Humberstone AJ, Porter CJH, Edwards GA, Charman WN. Formulation design and bioavailability assessment of lipidic self-emulsifying formulations of halofantrine. Int $J$ Pharm. 1998;167(1):155-164. doi:10.1016/S0378-5173(98)00054-4

28. Kumar B, Garg V, Singh S, et al. Impact of spray drying over conventional surface adsorption technique for improvement in micromeritic and biopharmaceutical characteristics of self-nanoemulsifying powder loaded with two lipophilic as well as gastrointestinal labile drugs. Powder Technol. 2018;326:425-442. doi:10.1016/j.powtec.2017.12.005

29. Jiang $\mathrm{CP}$, He X, Yang XL, et al. Intestinal absorptive transport of Genkwanin from Flos genkwa using a single-pass intestinal perfusion rat model. Am J Chin Med. 2014;42(2):349-359. doi:10.1142/ S0192415X14500232

30. Jain R, Duvvuri S, Kansara V, Mandava NK, Mitra AK. Intestinal absorption of novel-dipeptide prodrugs of saquinavir in rats. Int J Pharm. 2007;336(2):233-240. doi:10.1016/j.ijpharm.2006.11. 058

31. Shen J, Jin Y, Tian H, et al. Enhancement of oral bioavailability of akebia saponin D by destroying self-micelles and inhibiting multidrug resistance-associated protein mediated efflux. RSC $A d v$. 2016;6 (76):72439-72446. doi:10.1039/C6RA14427F

32. Gala U, Miller D, Williams RO. Improved dissolution and pharmacokinetics of abiraterone through KinetiSol ${ }^{\circledR}$ enabled amorphous solid dispersions. Pharmaceutics. 2020;12(4):357. doi:10.3390/ pharmaceutics 12040357

33. Kanehara K, Ohnuma S, Kanazawa Y, et al. The indole compound MA-35 attenuates tumorigenesis in an inflammation-induced colon cancer model. Sci Rep. 2019;9(1):12739. doi:10.1038/s41598-01948974-9

34. Thaker AI, Shaker A, Rao MS, Ciorba MA. Modeling colitis-associated cancer with azoxymethane (AOM) and dextran sulfate sodium (DSS. J Vis Exp. 2012;(67). doi:10.3791/4100.

35. Shon WJ, Lee YK, Shin JH, Choi EY, Shin DM. Severity of DSS-induced colitis is reduced in Ido1-deficient mice with down-regulation of TLR-MyD88-NF-kB transcriptional networks. Sci Rep. 2015;5:17305. doi:10.1038/srep17305

36. Nam SH, Kim JK. Tussilagone reduces tumorigenesis by diminishing inflammation in experimental colitis-associated colon cancer Biomedicines. 2020;8(4):86. doi:10.3390/biomedicines8040086

37. Kim JJ, Shajib MS, Manocha MM, Khan WI. Investigating Intestinal Inflammation in DSS-induced model of IBD. J Visual Exp. 2012;(60). doi: $10.3791 / 3678$.

38. Narain NK. Flavonoids from Vernonia fasciculata Michx. Isolation of genkwanin and a new flavone disaccharide, fasciculatin. $J$ Chem Soc Perkin 1. 1977;(9):1018-1020. doi:10.1039/p19770001018

39. Date AA, Nagarsenker MS. Design and evaluation of self-nanoemulsifying drug delivery systems (SNEDDS) for cefpodoxime proxetil. Int J Pharm. 2007;329(1-2):166-172. doi:10.1016/ j.ijpharm.2006.08.038

40. van Staden D, Du Plessis J, Viljoen J. Development of a self-emulsifying drug delivery system for optimized topical delivery of clofazimine. Pharmaceutics. 2020;12(6):523. doi:10.3390/ pharmaceutics 12060523
41. Krstić M, Medarević Đ, Đuriš J, Ibrić S. Self-nanoemulsifying drug delivery systems (SNEDDS) and self-microemulsifying drug delivery systems (SMEDDS) as lipid nanocarriers for improving dissolution rate and bioavailability of poorly soluble drugs. Lipid Nanocarriers Drug Target. 2018;473-508.

42. Lawrence MJ, Rees GD. Microemulsion-based media as novel drug delivery systems. Adv Drug Deliv Rev. 2012;64:175-193. doi:10.1016/j.addr.2012.09.018

43. Li P, Ghosh A, Wagner RF, Krill S, Joshi YM, Serajuddin ATM. Effect of combined use of nonionic surfactant on formation of oil-inwater microemulsions. Int J Pharm. 2005;288(1):27-34. doi:10.1016/ j.ijpharm.2004.08.024

44. Kassem AA, Mohsen AM, Ahmed RS, Essam TM. Selfnanoemulsifying drug delivery system (SNEDDS) with enhanced solubilization of nystatin for treatment of oral candidiasis: design, optimization, in vitro and in vivo evaluation. $J$ Mol Liq. 2016;218:219-232. doi:10.1016/j.molliq.2016.02.081

45. Elnaggar YSR, El-Massik MA, Abdallah OY. Self-nanoemulsifying drug delivery systems of tamoxifen citrate: design and optimization. Int J Pharm. 2009;380(1-2):133-141. doi:10.1016/j.ijpharm.2009.07.015

46. Kim RM, Jang DJ, Kim YC, et al. Flurbiprofen-loaded solid SNEDDS preconcentrate for the enhanced solubility, in-vitro dissolution and bioavailability in rats. Pharmaceutics. 2018;10(4):247. doi:10.3390/pharmaceutics 10040247

47. Sun $M$, Zhai X, Xue $K$, et al. Intestinal absorption and intestinal lymphatic transport of sirolimus from self-microemulsifying drug delivery systems assessed using the single-pass intestinal perfusion (SPIP) technique and a chylomicron flow blocking approach: linear correlation with oral bioavailabilities in rats. Eur J Pharm Sci. 2011;43(3):132-140. doi:10.1016/j.ejps.2011.04.011

48. Wagner AE, Will O, Sturm C, Lipinski S, Rosenstiel P, Rimbach G. DSS-induced acute colitis in C57BL/6 mice is mitigated by sulforaphane pre-treatment. J Nutr Biochem. 2013;24(12):2085-2091. doi:10.1016/j.jnutbio.2013.07.009

49. Zhang X, Wei L, Wang J, et al. Suppression colitis and colitis-associated colon cancer by anti-S100a9 antibody in mice. Front Immunol. 2017;8:1774. doi:10.3389/fimmu.2017.01774

50. Park JH, Kim JK. Pristimerin, a naturally occurring triterpenoid, attenuates tumorigenesis in experimental colitis-associated colon cancer. Phytomedicine. 2018;42:164-171. doi:10.1016/j.phymed.2018.03.033

51. Du WJ, Yang XL, Song ZJ, et al. Antitumor activity of total flavonoids from Daphne genkwa in colorectal cancer. Phytother Res. 2016;30(2):323-330. doi:10.1002/ptr.5540

52. Fuior E-V, Calin M. Nanoparticle-based delivery of polyphenols for the treatment of inflammation-associated diseases. Adv Aven Dev Novel Carriers Bioactives Biol Agents. 2020;343-382.

53. Collnot E-M, Ali H, Lehr C-M. Nano- and microparticulate drug carriers for targeting of the inflamed intestinal mucosa. $J$ Control Release. 2012;161(2):235-246. doi:10.1016/j.jconrel.2012.01.028

54. Mishra RK, Ahmad A, Kumar A, Vyawahare A, Raza SS, Khan R. Lipid-based nanocarrier-mediated targeted delivery of celecoxib attenuate severity of ulcerative colitis. Mater Sci Eng C. 2020;116.

55. Bastola R, Seo JE, Keum T, et al. Preparation of squalene oil-based emulsion adjuvants employing a self-emulsifying drug delivery system and assessment of mycoplasma hyopneumoniae-specific antibody titers in BALB/c mice. Pharmaceutics. 2019;11(12):667. doi:10.3390/pharmaceutics 11120667

56. Bennett-Lenane H, O'Shea JP, O'Driscoll CM, Griffin BT. A retrospective biopharmaceutical analysis of $>800$ approved oral drug products: are drug properties of solid dispersions and lipidbased formulations distinctive? J Pharm Sci. 2020;109:3248-3261. doi:10.1016/j.xphs.2020.08.008

57. O’Dwyer PJ, Box KJ, Koehl NJ, et al. Novel biphasic lipolysis method to predict in vivo performance of lipid-based formulations. Mol Pharm. 2020;17(9):3342-3352. doi:10.1021/acs.molpharmaceut. $0 \mathrm{c} 00427$ 
58. Siqueira Jørgensen S, Rades T, Mu H, Graeser K, Müllertz A. Exploring the utility of the chasing principle: influence of drug-free SNEDDS composition on solubilization of carvedilol, cinnarizine and R3040 in aqueous suspension. Acta Pharm Sin B. 2019;9 (1):194-201. doi:10.1016/j.apsb.2018.07.004

59. Kontogiannidou E, Meikopoulos T, Gika H, et al. In vitro evaluation of Self-Nano-Emulsifying Drug Delivery Systems (SNEDDS) containing Room Temperature Ionic Liquids (RTILs) for the oral delivery of amphotericin B. Pharmaceutics. 2020;12(8):699. doi:10.3390/ pharmaceutics12080699

60. Rani S, Rana R, Saraogi GK, Kumar V, Gupta U. Self-emulsifying oral lipid drug delivery systems: advances and challenges. AAPS PharmSciTech. 2019;20(3). doi:10.1208/s12249-019-1335-x

61. Williams HD, Sassene P, Kleberg K, et al. Toward the establishment of standardized in vitro tests for lipid-based formulations, part 4: proposing a new lipid formulation performance classification system. J Pharm Sci. 2014;103(8):2441-2455. doi:10.1002/jps.24067

62. ElShagea HN, ElKasabgy NA, Fahmy RH, Basalious EB. Freezedried Self-Nanoemulsifying Self-Nanosuspension (SNESNS): a new approach for the preparation of a highly drug-loaded dosage form. AAPS PharmSciTech. 2019;20(7). doi:10.1208/s12249-019-1472-2

63. Alhakamy NA, Fahmy UA, Ahmed OAA. Attenuation of benign prostatic hyperplasia by optimized tadalafil loaded pumpkin seed oil-based self nanoemulsion: in vitro and in vivo evaluation. Pharmaceutics. 2019;11(12):640. doi:10.3390/pharmaceutics11120640

64. Joyce P, Dening TJ, Meola TR, et al. Solidification to improve the biopharmaceutical performance of SEDDS: opportunities and challenges. Adv Drug Deliv Rev. 2019;142:102-117. doi:10.1016/j. addr.2018.11.006

65. Stillhart C, Dürr D, Kuentz M. Toward an improved understanding of the precipitation behavior of weakly basic drugs from oral lipid-based formulations. J Pharm Sci. 2014;103(4):1194-1203. doi:10.1002/ jps. 23892

66. Williams HD, Sassene P, Kleberg K, et al. Toward the establishment of standardized in vitro tests for lipid-based formulations, part 1 : method parameterization and comparison of in vitro digestion profiles across a range of representative formulations. J Pharm Sci. 2012;101 (9):3360-3380. doi:10.1002/jps.23205
67. McCartney F, Jannin V, Chevrier S, et al. Labrasol (R) is an efficacious intestinal permeation enhancer across rat intestine: ex vivo and in vivo rat studies. $J$ Control Release. 2019;310:115-126. doi:10.10 16/j.jconrel.2019.08.008

68. Kazi M, Alhajri A, Alshehri SM, et al. Enhancing oral bioavailability of apigenin using a Bioactive Self-Nanoemulsifying Drug Delivery System (Bio-SNEDDS): in vitro, in vivo and stability evaluations. Pharmaceutics. 2020;12(8):749. doi:10.3390/pharmaceutics12080 749

69. O’Driscoll CM, Griffin BT. Biopharmaceutical challenges associated with drugs with low aqueous solubility-The potential impact of lipid-based formulations. Adv Drug Deliv Rev. 2008;60(6):617-624. doi:10.1016/j.addr.2007.10.012

70. van der Merwe J, Steenekamp J, Steyn D, Hamman J. The role of functional excipients in solid oral dosage forms to overcome poor drug dissolution and bioavailability. Pharmaceutics. 2020;12(5):393. doi:10.3390/pharmaceutics 12050393

71. Ukai H, Iwasa K, Deguchi T, Morishita M, Katsumi H, Yamamoto A. Enhanced intestinal absorption of insulin by Capryol 90, a novel absorption enhancer in rats: implications in oral insulin delivery. Pharmaceutics. 2020;12(5):462. doi:10.3390/pharmaceutics 12050462

72. He X, Song ZJ, Jiang CP, Zhang CF. Absorption properties of luteolin and apigenin in Genkwa Flos using in situ single-pass intestinal perfusion system in the rat. Am J Chin Med. 2017;45 (8):1745-1759. doi:10.1142/S0192415X1750094X

73. Karki R, Man SM, Kanneganti TD. Inflammasomes and cancer. Cancer Immunol Res. 2017;5(2):94-99. doi:10.1158/2326-6066.CIR-16-0269

74. Antoni L, Nuding S, Wehkamp J, Stange EF. Intestinal barrier in inflammatory bowel disease. World J Gastroenterol. 2014;20 (5):1165-1179. doi:10.3748/wjg.v20.i5.1165

75. Jin HF, Guo J, Liu JM, et al. Anti-inflammatory effects and mechanisms of vagal nerve stimulation combined with electroacupuncture in a rodent model of TNBS-induced colitis. Am J Physiol Gastroint Liver Physiol. 2017;313(3):G192-G202. doi:10.1152/ajpgi.00254.2016

76. Biagioli M, Laghi L, Carino A, et al. Metabolic variability of a multispecies probiotic preparation impacts on the anti-inflammatory activity. Front Pharmacol. 2017;8. doi:10.3389/fphar.2017.00505

\section{Publish your work in this journal}

Drug Design, Development and Therapy is an international, peerreviewed open-access journal that spans the spectrum of drug design and development through to clinical applications. Clinical outcomes, patient safety, and programs for the development and effective, safe, and sustained use of medicines are a feature of the journal, which has also been accepted for indexing on PubMed Central. The manuscript management system is completely online and includes a very quick and fair peer-review system, which is all easy to use. Visit http://www. dovepress.com/testimonials.php to read real quotes from published authors. 